\title{
Bioactive components and health effects of pecan nuts and their by- products: a review
}

\author{
Emilio Alvarez-Parrilla ${ }^{\mathrm{a}}$, Rafael Urrea-López ${ }^{\mathrm{b}}$ and Laura A. de la Rosa ${ }^{\mathrm{a}^{*}}$
}

\begin{abstract}
aDepartment of Chemical Biological Sciences, Universidad Autónoma de Ciudad Juárez, AnilloEnvolvente del Pronaf y Estocolmo, s/n, Cd, 32310 Juárez, Chihuahua, Mexico

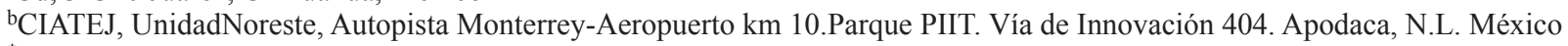

*Corresponding author: Laura A. de la Rosa, Department of Chemical Biological Sciences, Universidad Autónoma de Ciudad Juárez, AnilloEnvolvente del Pronaf y Estocolmo, s/n, Cd, 32310 Juárez, Chihuahua, Mexico. Tel: (+52) 656-688-1800 ext 1563; E-mail: 1delaros@ uacj.mx
\end{abstract}

DOI: $10.31665 / J F B .2018 .1127$

Received: January 18, 2018; Revised received \& accepted: January 21, 2018

Citation: Alvarez-Parrilla, E., Urrea-López, R., and de la Rosa, L.A. (2018). Bioactive components and health effects of pecan nuts and their by-products: a review. J. Food Bioact. 1: 56-92.

\begin{abstract}
Pecan is a North American native tree that produces a stone fruit or kernel, commonly known as pecan nut, which is highly valuable worldwide due to its sensory quality, and health promoting properties derived from the presence of mono- and polyunsaturated fatty acids, tocopherols and monomeric and polymeric polyphenolic compounds. The increase in the demand for pecan nut leads to an increase in by-products such as leaves, cake and principally nutshell, which have high contents of bioactive components, making them interesting raw materials to produce nutraceuticals with health benefits. The phytochemical content of pecan oil and kernel, as well as that of the main pecan by-products is discussed in detail, paying special attention to the presence of individual polyphenols with monomeric and polymeric structures. Finally, studies regarding the biological activity and potential use of pecan oil, kernel and by-products are summarized and discussed.
\end{abstract}

Keywords: Pecan kernel; pecan oil; nutshells; polyphenols; tocopherols; oxidative stress.

\section{Introduction}

Tree nuts have gained recognition for their health benefits in the last ten to fifteen years. They were first recognized for their role in reducing the risk for cardiovascular disease (CVD), but high nut consumption is also inversely associated to all-cause and cancer mortality, type 2 diabetes in women(Lamuel-Raventos and St. Onge, 2017), decreased cognitive function, risks of asthma and inflammatory bowel disease, among other benefits(Alasalvar and Bolling, 2015). Interestingly, despite being energy dense due to their high lipid content, nuts have a tendency to lower bodyweight and fat mass(Rajaram and Sabaté, 2006). Tree nuts may also have prebiotic properties due to their high content of fiber and polymeric polyphenols (Lamuel-Raventos and St. Onge, 2017). Some of the most common tree nuts are almond, Brazil nut, cashew, hazelnut,macadamia, pecan, pine nut, pistachio, and wal- nut. Among them, walnut and almond are both the most studied and economically important species (Chang et al., 2016). Pecan nuts (Caryaillinoinensis) are a major agricultural product of some states in northern Mexico and Southern United States. They are also important in Australia and are being introduced to other countries, including China. Pecan nuts are usually consumed raw or as an ingredient of some specialty dishes, more recently they have also been used to extract oil, which is sold as a gourmet food ingredient. Pecans are greatly appreciated for their sensory attributes and could be an excellent alternative to increase nut consumption, and its corresponding health benefits, in regions of low nut intake. The present review summarizes all the available data on the content of bioactive compounds in pecan nut, pecan oil and also in several by-products of the pecan industry including nutshells and leaves. It also describes the principal findings on the biological activity and some of the biochemical mechanisms of the pecan nut, 


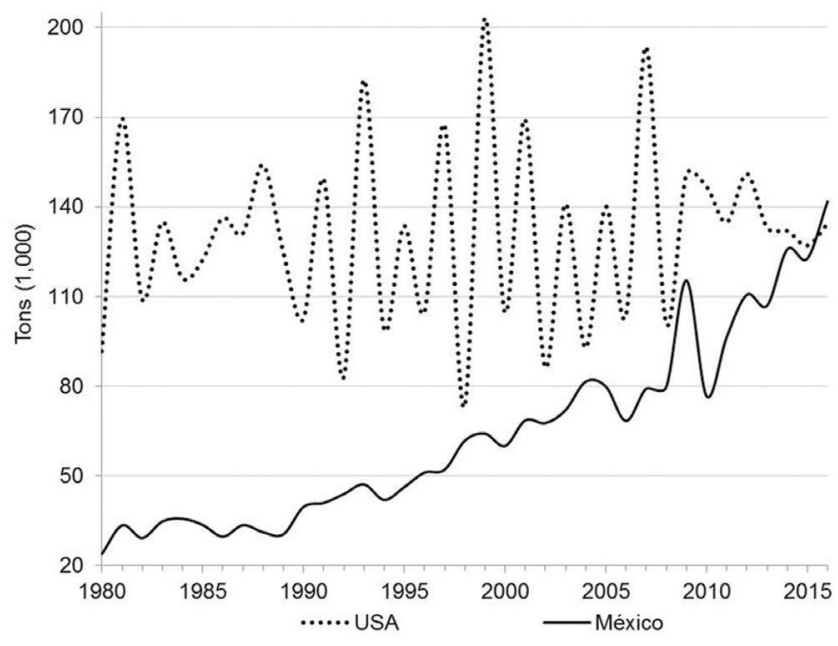

Figure 1. Pecan production in Mexico and United States from 1980 to 2016.

oil, and extracts of the edible kernel and by-products.

\section{General characteristics of pecan}

The pecan tree [Caryaillinoinensis (Wangenh.) K. Koch] belonging to the walnut family (Juglandaceae), is a large deciduous tree of up to 50 meters high and up to 200 years of life, with a long juvenile stage (5 to 12 years) (Stone, 1997). The pecan tree is a native species of North America, where the records of pollen found in the soil indicate its natural distribution 16,000 years ago (Wells, $2017 \mathrm{~b}$ ). The native range of pecan trees covers a wide geographical area of United States and México, with a considerable genetic diversity, probably due to the discontinuous distribution of many isolated populations, which is reflected in cultivars with a wide range of cold adaptation (Wood et al., 1998).

Pecan tree is an angiosperm plant, with monoecious flowers distributed at different locations on the same tree, male are slender catkin (staminate flowers), meanwhile, the female are small erect clusters (pistillate flowers) which mature asynchronously and are pollinated by the wind. The pecan tree produces stone fruits, which are characterized by being monosperm with dehiscent pericarp (husk or shuck), with elliptical or oblong endocarp hardened (shell) of brown color with black marks near the apex that covers the dicotyledon kernel (Burns et al., 1990; Vendrame and Wetzstein, 2005). These kernels covered by the hard brown shell are known as the pecan nuts.

Pecan tree is a species highly valued for its pecan nuts, which have been part of the human diet for approximately 10,000 years (Wells, 2017b). Cultivation of pecan trees is relatively recent, with northern Mexico being the first place where it was planted at the end of 1600 in the town of Bustamante (Sparks, 2005). However, the greatest boom in pecan nut production has occurred in the last century in the USA and Mexico as a result of improved production practices (Wood et al., 1990), the availability of machinery for pruning, fumigation and transplanting activities, the improvement of early cultivars and higher productivity (Wells, 2014), and the rapid growth of international demand, mainly in the Asian markets (Lillywhite et al., 2014).

The increase in global demand has transformed the millenarian practice of harvesting natural forests to the establishment of large plantations in their area of natural origin, in the southern fringe of the United States and northern Mexico. Currently the USA and Mexico concentrate the highest production of pecan nut worldwide, with more than $90 \%$ of production followed by far by South Africa and Australia (International Nut and Dried Fruit Council, 2016).

Mexico has been the country with the greatest increase in its pecan trees sown area in the last decades. From 1980 Mexico has increased by 2.9 times the area planted with pecan trees, going from 38,904 hectares $(\mathrm{Ha})$ to $114,464 \mathrm{Ha}$ in 2016 . The recent rise in the number of pecan trees in Mexico has resulted in an increase of 5.9 times in the total production of pecan nuts, from 23,882 tons in 1980 to 141,817 in 2016 (in-shell) (SIAP, 2016), equalizing and surpassing pecan nut production of the United States since 2016 (Figure 1) (Economic Research Service, 2017a). Mexico is the leading exporter of pecan nut worldwide. Of the total volume produced in Mexico, three quarters are exported, more than $90 \%$ to the United States. By $2014,56 \%$ of the total volume of pecan exports worldwide came from Mexico and 42\% from United States (International Nut and Dried Fruit Council, 2016). Pecan nut exports from these two countries generated $\$ 403$ and $\$ 506$ million in foreign exchange income for Mexico and United States, respectively (Economic Research Service, 2017b; Secretaría de Economía, 2015).

A high proportion of the fruit of the pecan tree is not edible, so the recent global increase in pecan nut production also leads to increased production of by-products like husk and nutshell. The husk represents approximately 25 to $30 \%$ of the total mass of the pecan fruit, and the nutshell represents up to $49 \%$ of the nut (Idowu et al., 2017).

The pecan tree is one of the few native plant species of North America that has become an important crop today. In 1876 appeared the "Centennial" pecan cultivar, a milestone in pecan nut production, this was the first recognized pecan variety; and also the first vegetatively propagated pecan cultivar; and the first pecan variety planted in the form of a commercial orchard with the aim of obtaining nuts for sale (Wells, 2017a). Since then, intense pecan breeding programs have been developed to select those cultivars with the best morphological characteristics, such as those related to nut size, ease of shell opening, biochemical features related to taste or resistance to insects and diseases, and physiological traits like growth and production habits.

Many varieties have been developed, mainly in the USA. Seventy five varieties of pecan nut have been registered in the plant variety database (PLUTO) of the international union for the protection of new varieties of plants (UPOV), with 37 varieties corresponding to the USA, 22 to Argentina, 12 to Turkey, 2 to Israel and 1 to Mexico (UPOV, 2017). The USDA National Collection of Genetic Resources for Pecans and Hickories houses a collection of more than 300 pecan cultivars grown in the USA (USDA, 2017).

The new developed varieties have been adopted in plantations. From the late nineteenth century until the Second World War, pecan varieties Stuart, Schley, Pabst, and Alley dominated the pecan industry of the southeast USA (Wells, 2017a). In the 90's approximately half of the improved varieties that were planted in the USA corresponded to Stuart, Western Schley and Desirable, with 22, 14.6 and $10.9 \%$ respectively. During this period, the main varieties sown for commercial production in the western region of the USA (Burns et al., 1990; Herrera, 1995; Wells, 2017a) and northern Mexico (Núñez et al., 2001; Orona-Castillo et al., 2006) were mostly "Western Schley" and "Wichita" the latter is used mainly as a pollinator, due to the incomplete dicogamy of the species. From 2010 to 2014 the planting of 14 to 30 different cultivars was reported in Georgia, the main producing state of the USA, with 
Table 1. Proximal composition and micronutrient content of the pecan nut (content in $100 \mathrm{~g}$ of nut)

\begin{tabular}{|c|c|c|}
\hline Nutrient & Unit & Content \\
\hline \multicolumn{3}{|l|}{ Proximate composition } \\
\hline Water & g & 3.52 \\
\hline Energy & kcal & 691 \\
\hline Protein & g & 9.17 \\
\hline Total lipid (fat) & $\mathrm{g}$ & 71.97 \\
\hline Ash & g & 1.49 \\
\hline Carbohydrate, by difference & g & 13.86 \\
\hline Fiber, total dietary & g & 9.6 \\
\hline Sugars, total & g & 3.97 \\
\hline Sucrose & g & 3.9 \\
\hline Glucose (dextrose) & g & 0.04 \\
\hline Fructose & g & 0.04 \\
\hline Starch & g & 0.46 \\
\hline \multicolumn{3}{|l|}{ Minerals } \\
\hline Calcium, Ca & $\mathrm{mg}$ & 70 \\
\hline Iron, Fe & $\mathrm{mg}$ & 2.53 \\
\hline Magnesium, Mg & $\mathrm{mg}$ & 121 \\
\hline Phosphorus, $\mathrm{P}$ & $\mathrm{mg}$ & 277 \\
\hline Potassium, $\mathrm{K}$ & $\mathrm{mg}$ & 410 \\
\hline Sodium, $\mathrm{Na}$ & $\mathrm{mg}$ & 0 \\
\hline Zinc, Zn & $\mathrm{mg}$ & 4.53 \\
\hline Copper, Cu & $\mathrm{mg}$ & 1.2 \\
\hline Manganese, $\mathrm{Mn}$ & $\mathrm{mg}$ & 4.5 \\
\hline Selenium, Se & $\mu \mathrm{g}$ & 3.8 \\
\hline Fluoride, $\mathrm{F}$ & $\mu \mathrm{g}$ & 10 \\
\hline \multicolumn{3}{|l|}{ Vitamins } \\
\hline Vitamin C, total ascorbic acid & $\mathrm{mg}$ & 1.1 \\
\hline Thiamin & $\mathrm{mg}$ & 0.66 \\
\hline Riboflavin & $\mathrm{mg}$ & 0.13 \\
\hline Niacin & $\mathrm{mg}$ & 1.167 \\
\hline Pantothenic acid & $\mathrm{mg}$ & 0.863 \\
\hline Vitamin B-6 & $\mathrm{mg}$ & 0.21 \\
\hline Folate, total & $\mu \mathrm{g}$ & 22 \\
\hline Choline, total & $\mathrm{mg}$ & 40.5 \\
\hline Betaine & $\mathrm{mg}$ & 0.7 \\
\hline Vitamin A, RAE & $\mu \mathrm{g}$ & 3 \\
\hline Vitamin A, IU & IU & 56 \\
\hline Vitamin E (alpha-tocopherol) & $\mathrm{mg}$ & 1.4 \\
\hline Vitamin K (phylloquinone) & $\mu \mathrm{g}$ & 3.5 \\
\hline
\end{tabular}

Abbreviations: Kcal, Kilocalories; RAE, retinol activity equivalents; IU, international units. Adapted from USDA (2016). the Desirable and Pawnee cultivars being the most planted in that period (Wells, 2014).

According to the food composition database of the United States Department of Agriculture (USDA, 2016) the proximal composition of pecans is characterized by a high content of lipids followed by carbohydrates, dietary fiber and proteins (Table 1). Pecan nut is a natural source of minerals and vitamins, basic in human nutrition. Among the most abundant minerals are potassium, phosphorus, and magnesium, with 410, 277 and $121 \mathrm{mg}$ per 100 $\mathrm{g}$, respectively, while the least abundant mineral is sodium. Of the vitamins present in the pecan nut, the most abundant are choline, vitamin $\mathrm{E}$ ( $\alpha$-tocopherol), and niacin with $40.5,1.4$ and $1.167 \mathrm{mg}$ per $100 \mathrm{~g}$, respectively.

It has been observed that phytochemical contents in pecan nuts vary widely according to cultivars, the environment in which the plants grow, and other characteristics of the trees. Also, some important phytochemicals are concentrated in the lipid fraction of the pecan nut, while others are found mainly in the oil-free portion or in the non-edible by-products. Advances in the capacity of analysis of bioactive compounds in pecan nuts can be a powerful tool to support the process of genetic improvement of new varieties based on the existing genetic diversity.

\section{Phytochemicals in pecan oil}

Pecan nut oil is an important source of monounsaturated and polyunsaturated fatty acids (MUFA and PUFA, respectively) and tocopherols. It also contains other bioactive components such as phytosterols, phospholipids, sphingolipids, squalene, polyphenols and low amounts of carotenoids and tocotrienols. Pecan oil is nowadays a commercial product well appreciated as a cosmetic and gourmet food ingredient (Salvador et al., 2016; Scapinello et al., 2017) and whose popularity is increasing due to its potential health benefits (Gong et al., 2017). Commercial pecan nut oil is usually obtained by mechanical pressing and, due to its novelty, information on its composition is scarce in the scientific literature and no information is yet available from the USDA National Nutrient Database for Standard Reference (Gong et al., 2017). Although commercial pecan oil is a relatively new product, several studies have investigated the composition and phytochemicals present in non-commercial pecan oil and analyzed the effect of different extraction conditions and techniques as well as the characteristics of the nuts from which the oil is obtained. Table 2 summarizes the main findings of these studies.

Oleic and linoleic acids are the major components of pecan oil and their abundance is negatively correlated since linoleic acid is synthesized from oleic acid existing in oilseeds (Toro-Vazquez et al., 1999). Oleic acid is an $\omega-9$ MUFA; it is usually present in higher amounts than linoleic acid ( $\omega-6$ PUFA); this is a desirable characteristic because oils rich in oleic acid possess a higher oxidative stability than oils rich in linoleic acid and other PUFA (Miraliakbari and Shahidi, 2008c; Toro-Vazquez et al., 1999). However, a great variation in the content of these fatty acids has been reported in the scientific literature: they can range from 38.2 to $78.1 \%$ oleic acid and 13.6 to $50.3 \%$ linoleic acid (see Table 2). This wide variation is mostly due to the pecan cultivar, although other factors or combination of factors such as growing location, tree age, year of harvest, and ripening state of the pecan nut may also have a large impact (see references in Table 2). It is apparent that the effect of the oil extraction technique or conditions on the content of oleic and linoleic acids is marginal compared with their wide natural variations in samples of different origins and cultivars. The high- 


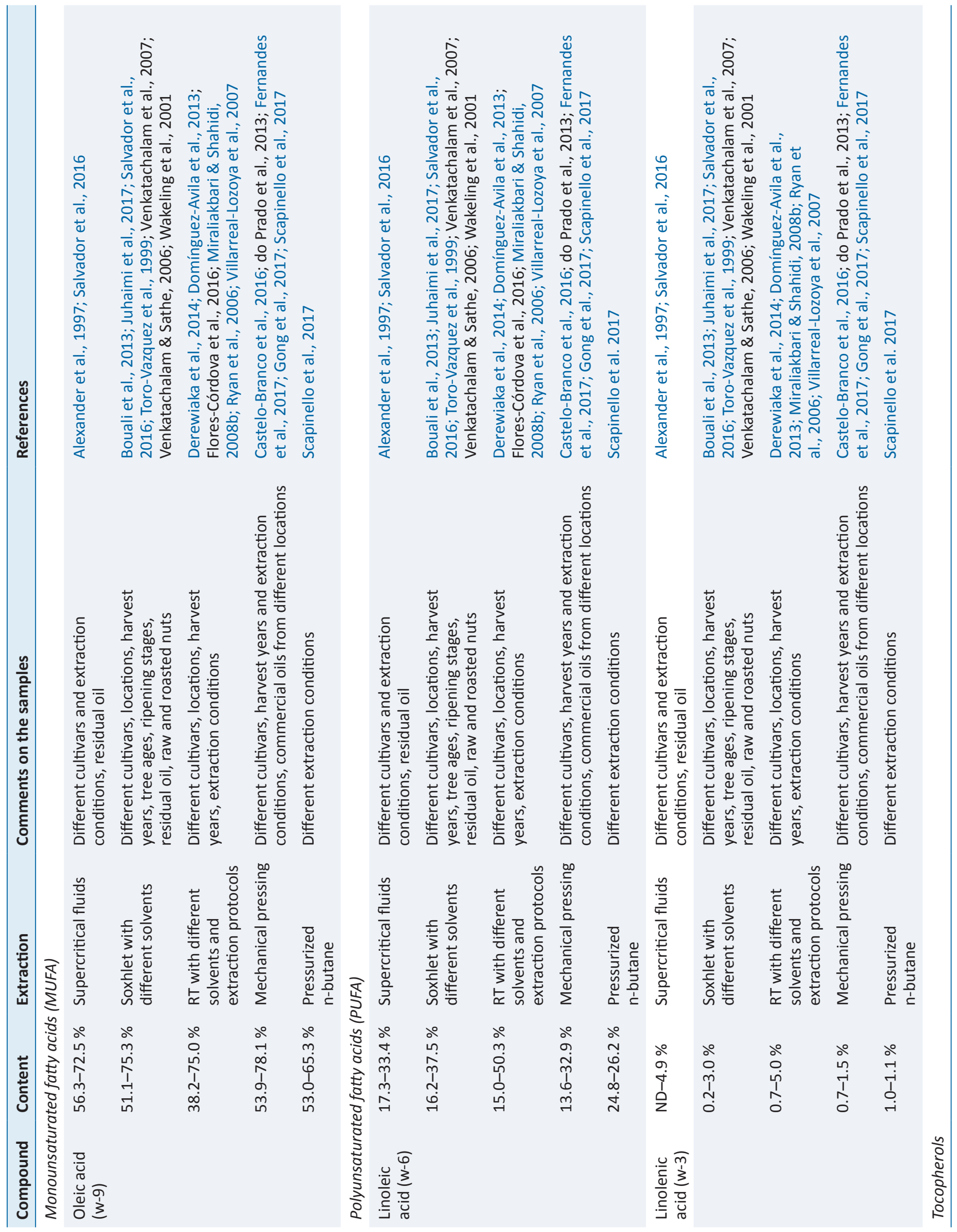




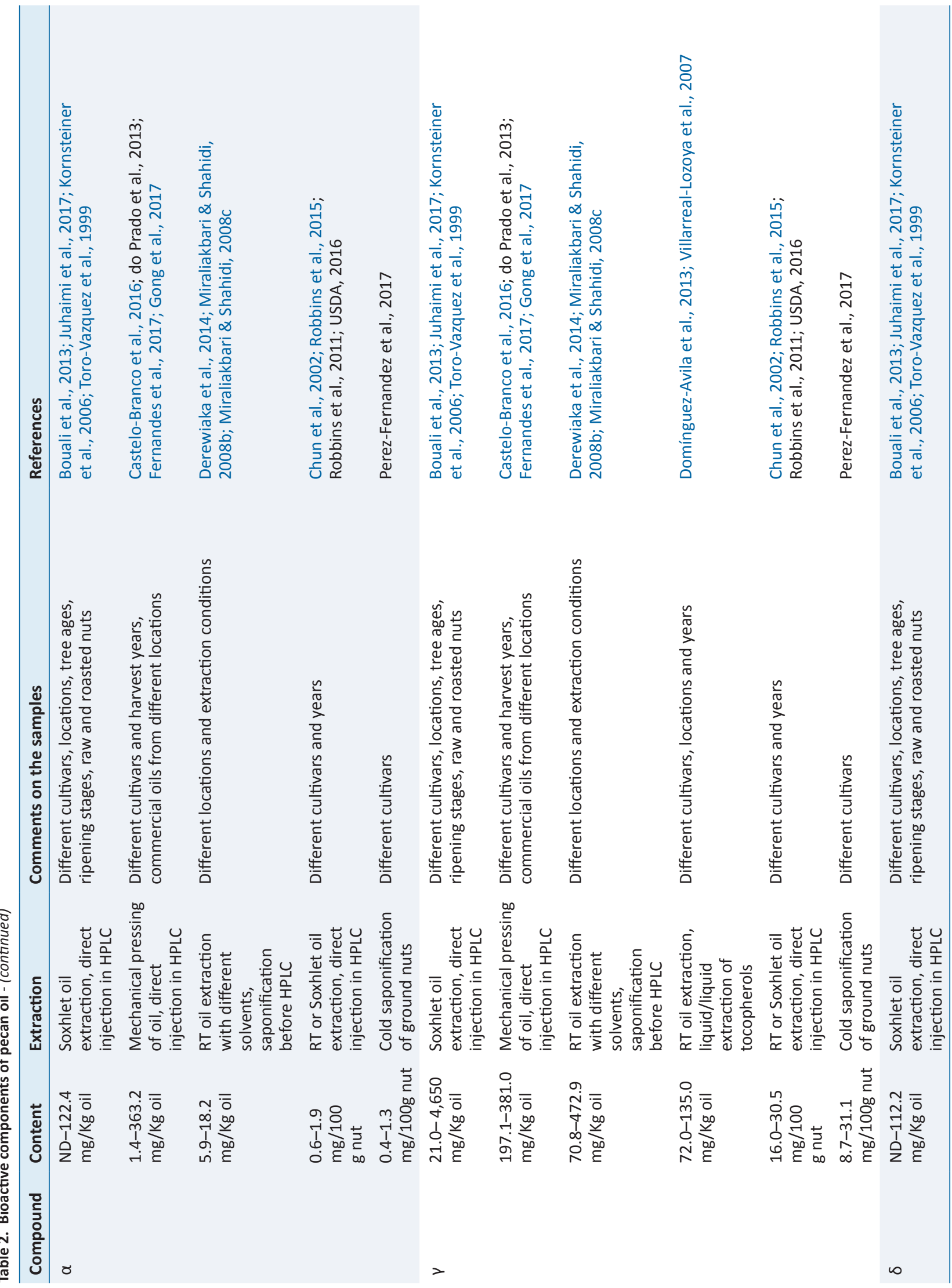




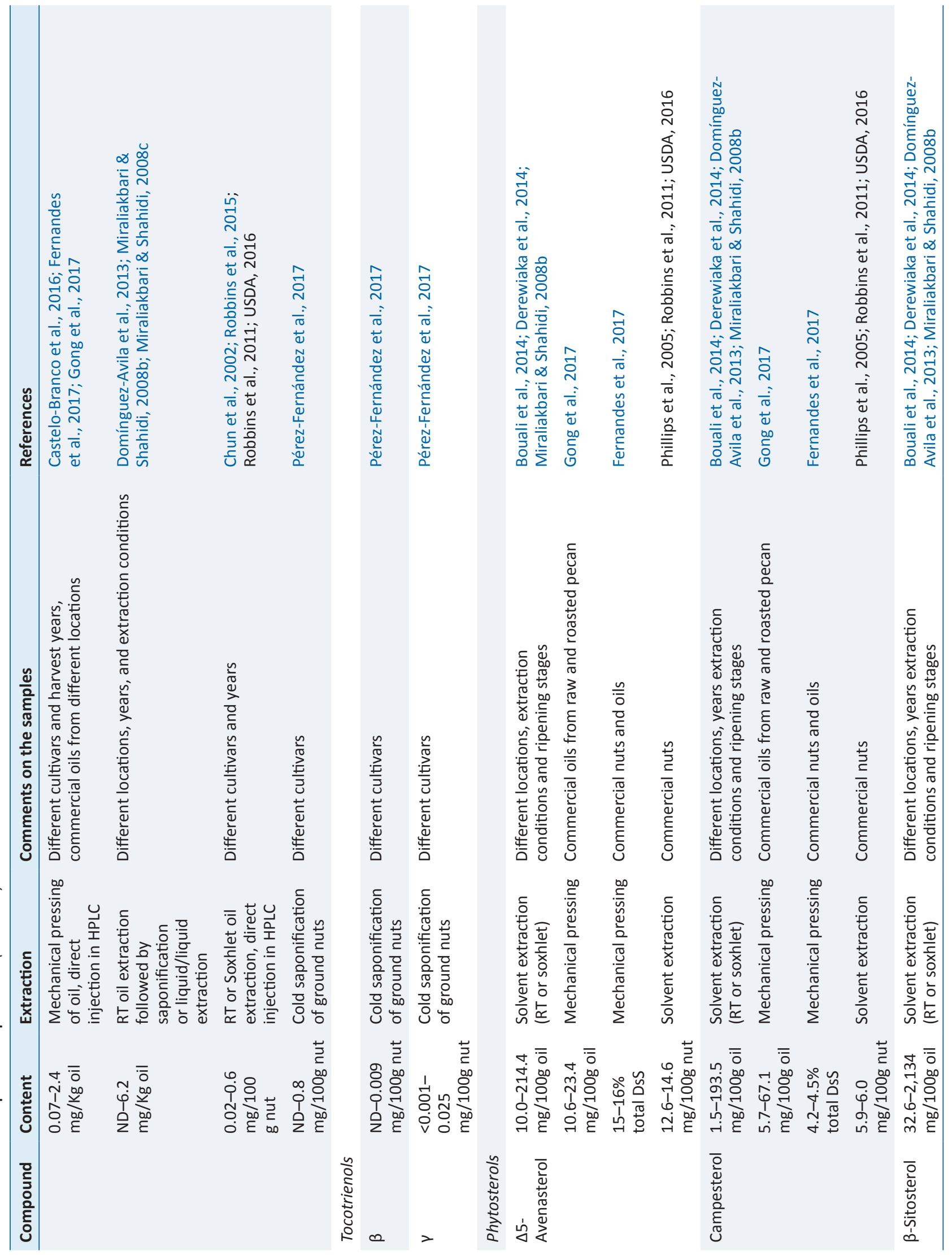



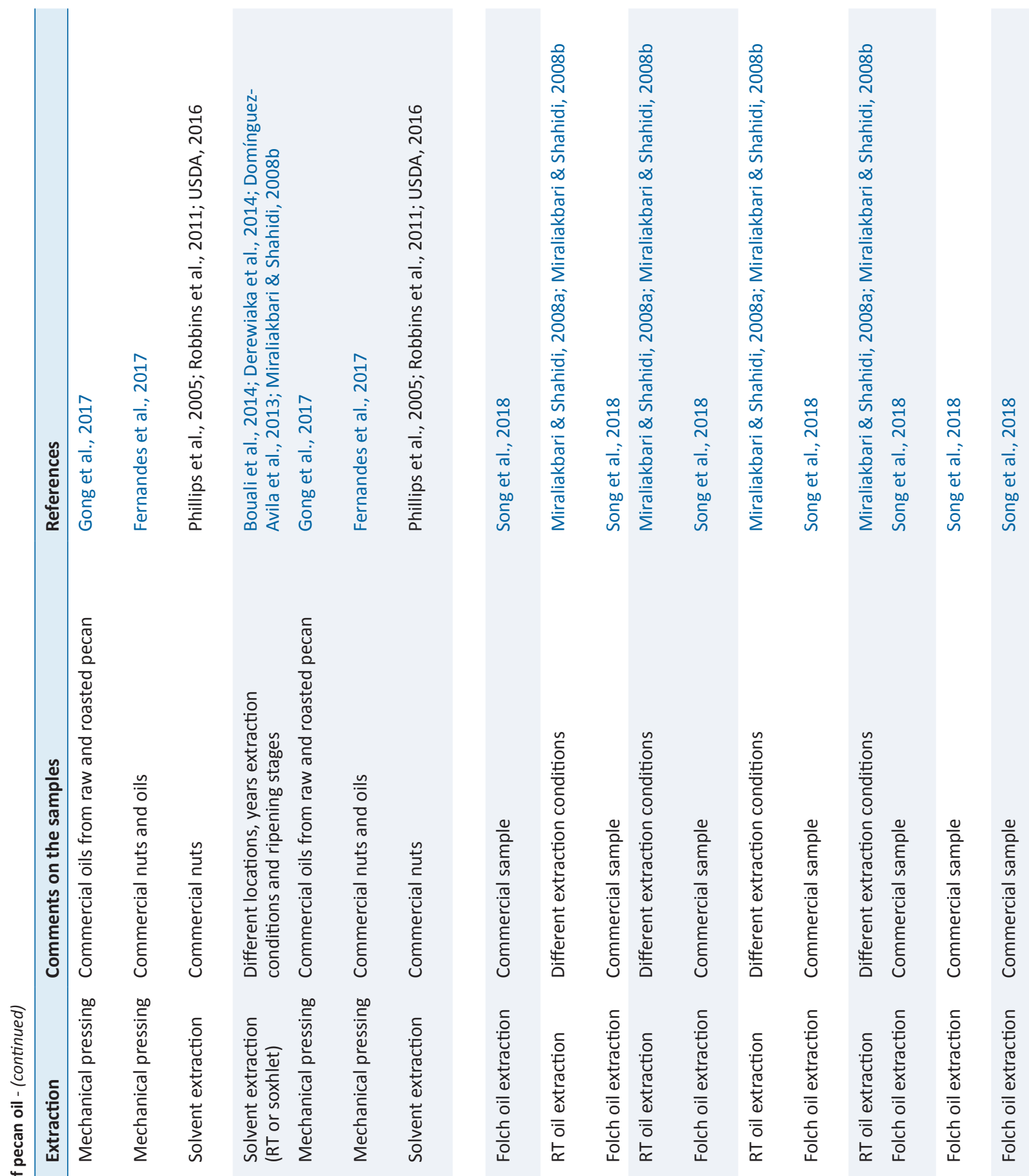

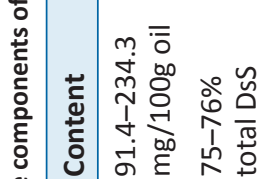
ㄱ:
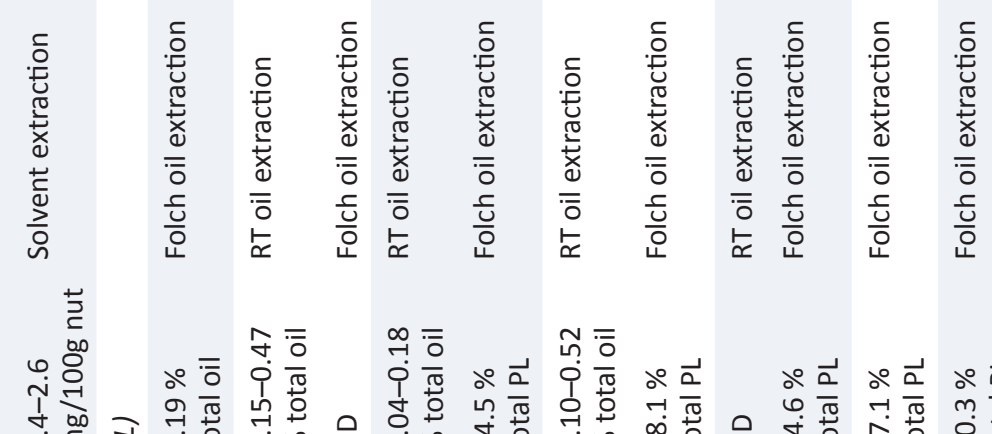

安 $\overline{\overline{0}}$

$\stackrel{\infty}{\rightarrow} \overline{0}$

กำ
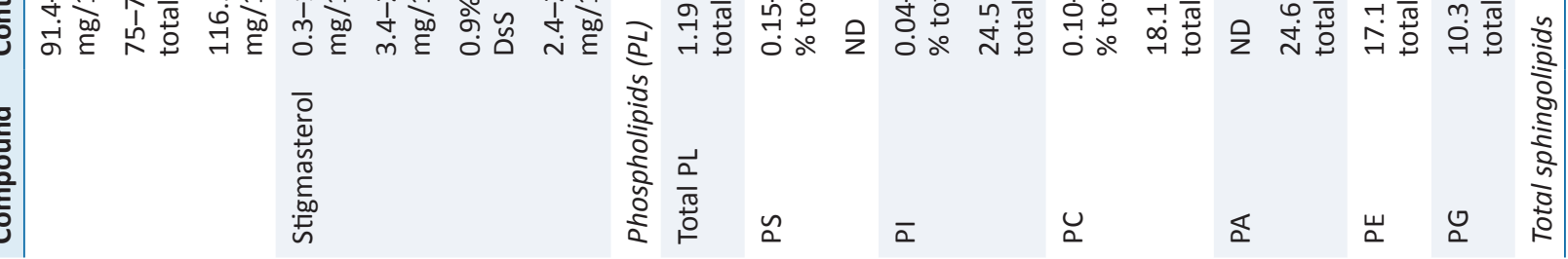
est oleic/linoleic ratios (5.0 and higher) have been reported in oil extracted by cold-pressing of pecan nuts native to southern Brazil (Scapinello et al., 2017) and in oil obtained by solvent extraction of nuts from the Shawnee cultivar grown in southern USA (Villarreal-Lozoya et al., 2007). The lowest ratio (0.8, showing more linoleic than oleic acid) was reported in solvent-extracted oil from samples of the Western Schley cultivar grown in northern Mexico (Flores-Córdova et al., 2017) and from commercial nuts in Ireland (Ryan et al., 2006).

Linolenic acid ( $\omega-3$ PUFA) is also synthesized from oleic acid, however their inverse correlation is not as strong as that between oleic and linoleic. Linolenic acid content in pecan oil ranges from undetectable to $5 \%$, the lowest contents (under $2 \%$ ) have been reported in oils obtained by mechanical pressing, including commercial oils, and residual oils recovered by supercritical fluid extraction (SFE) of the pecan cakes obtained as end product of commercial oil extraction (Salvador et al., 2016). Although this low linolenic acid could be in part attributed to characteristics of the cultivar (as in the case of oleic and linoleic acids), the results of (Scapinello et al., 2017) showed that, extraction of the same samples using pressurized $n$-butane yielded oil with higher levels of linolenic acid than those obtained in cold-pressed oil. (Salvador et al., 2016) also found a better recovery of linolenic acid in oil obtained by Soxhlet extraction than in oil obtained by SFE. In contrast, (Alexander et al., 1997) found high linolenic acid content $(4.9 \%)$ in oil obtained by SFE from nuts of the Wichita cultivar (grown in central USA) and observed that the extraction conditions had a stronger effect than the cultivar. High linolenic acid content $(5 \%)$ was also found in solvent-extracted oil from nuts of the Western Schley cultivar grown in northern Mexico, where the content of this fatty acid was highly affected by the year of harvest (Domínguez-Avila et al., 2013).

Tocopherols are lipid-soluble antioxidants with strong bioactive properties. Tocopherols and their unsaturated analogs, tocotrienols, are all members of the vitamin E family. Until recently, $\alpha$-tocopherol has been considered as the most active form of vitamin E; however, recent evidence has highlighted a very important role of other analogs, especially $\gamma$-tocopherol, in many of the biological actions of vitamin E (Mathur et al., 2015). Tocopherols are not only valuable for their bioactive properties but also for their impact in oil quality, since their presence can increase the oil's oxidative stability. Tocopherol concentration in nut oils can be used as a predictor of oxidative stability (Castelo-Branco et al., 2016) and unsaturation (Gong et al., 2017). For oxidative stability, $\gamma$-tocopherol showed the greatest influence, while $\delta$-tocopherol concentration was the best predictor for oil unsaturation.

Pecan nut and oil are some of the major sources of dietary $\gamma$-tocopherol, with varying levels of $\alpha$-tocopherol (see Table 2). Most studies report low content of $\alpha$-tocopherol in pecan nut and oil: from undetectable to under $20 \mathrm{mg} / \mathrm{kg}$ of oil, or $0.6-2.9 \mathrm{mg} / 100$ $\mathrm{g}$ of kernel. Variations can be attributed to differences in cultivars, environmental and analytical factors. Considerably higher content of $\alpha$-tocopherol (between 70.0 and $122.4 \mathrm{mg} / \mathrm{kg}$ oil) was found in pecan nuts native from the northern-central region of Mexico (cultivar not specified), although one particular sample from this study showed undetectable levels of $\alpha$-tocopherol, indicating a high variability of the native pecan populations (Toro-Vazquez et al., 1999). High levels of this analogue were also reported in commercial oils; in fact, in three of four pecan oil samples, $\alpha$-tocopherol was the predominant analogue, which is inconsistent with the natural distribution of these compounds in pecan $(\gamma>\alpha>\delta \approx \beta)$, suggesting the possibility of adulteration (Gong et al., 2017). The cultivar or geographical origin of the nuts used as source of these commercial oils was not mentioned by the oil producers. 
$\gamma$-Tocopherol is one of the major bioactive compounds found in pecan and pecan oil. It ranges from 21 to more than $400 \mathrm{mg} /$ $\mathrm{kg}$ of oil or 16.0 to $30.5 \mathrm{mg} / 100 \mathrm{~g}$ of kernel; although a study by Juhaimi et al (Juhaimi et al., 2017) reported values between 3,090 and $4,650 \mathrm{mg} / \mathrm{kg}$ of oil extracted from raw and roasted pecans obtained from Turkey (the cultivar was not mentioned in the paper). These authors did not detect any other tocopherol analogues in their samples and observed that microwave roasting reduced the $\gamma$-tocopherol content more than conventional oven roasting. (Gong et al., 2017) quantified all tocopherol analogues in commercial oils obtained from raw and roasted pecans and, although they concluded that roasting tree nuts before processing was not associated with a clear effect on total tocopherol contents in the finished oils, they did find a small but significant decrease of $\gamma$-tocopherol in oil obtained from roasted pecans compared to oil obtained from raw material. Other authors found that $\gamma$-tocopherol and other tocopherol analogues $(\alpha$ and $\delta$ ) also decreased in the oil of nuts as their rippening stage advanced from 20 to 27 weeks after flowering; the final decrease of $\gamma$-tocopherol was less than $25 \%$ (Bouali et al., 2013). Other factors that affect the $\gamma$-tocopherol levels of pecan nuts are the cultivar, year of harvest, and, when expressed in terms of whole kernel, the oil content of the sample; however, from the analysis of Table 2 and references therein it is apparent that the greatest source of variation is the location in which the sample was grown or purchased, and the experimental and analytical conditions for oil extraction and tocopherol purification and quantification.

Minor tocopherol analogues reported in pecan are $\delta$ - and $\beta$-tocopherols. $\delta$-Tocopherol ranges from undetectable to less than $10 \mathrm{mg} / \mathrm{kg}$ of oil (similar contents have been reported in whole kernel basis) although one study found high levels (112.2 mg/ $\mathrm{kg}$ oil) in Mexican native pecan populations (Toro-Vazquez et al., 1999). $\beta$-Tocopherol is ignored in many studies since, when analysis is carried out by reversed phase HPLC it co-elutes with $\gamma$-tocopherol; however, several works have quantified it by normal phase HPLC, showing $\beta$-tocopherol levels are similar to those of $\delta$-tocopherol(Chun et al., 2002; Gong et al., 2017; Pérez-Fernández et al., 2017). Tocotrienols, the unsaturated forms of vitamin $\mathrm{E}$ are found only in low amounts in some tree nuts. No tocotrienols were detected in different pecan cultivars grown in southern USA (Chun et al., 2002; Robbins et al., 2015). (Gong et al., 2017) were also unable to detect tocotrienols in commercial pecan oils or in commercial oils from other tree nut species. However, (PérezFernández et al., 2017) were able to quantify $\beta$ - and $\gamma$-tocotrienols (in the range of $<1-25 \mu \mathrm{g} / 100 \mathrm{~g}$ kernel) in three pecan cultivars (Stuart, Sioux and Pawnee) grown in an experimental farm in Italy, using cold saponification of ground kernels as the extraction procedure for tocols (tocopherols and tocotrienols) and reversed phase HPLC coupled to atmospheric pressure ionization tandem mass spectrometry (APCI-MS/MS) for identification and quantification.

Phytosterols are plant-derived compounds structurally related to cholesterol. For this reason they can interfere with cholesterol absorption and are known for their ability to reduce serum cholesterol. Pecan nuts are good sources of phytosterols of which, $\beta$-sitosterol is the most abundant (approximately $75 \%$ of total desmethylsterols), followed by $\Delta 5$-avenasterol (approximately $15 \%$ of total desmethylsterols), according to (Fernandes et al., 2017) and other references in Table 2. A large variability of $\beta$-sitosterol contents has been reported in pecan oils obtained by solvent extraction from nuts of different cultivars and geographical origins: from $32.6 \mathrm{mg} / 100 \mathrm{~g}$ oil in Western Schley nuts grown in northern Mexico (Domínguez-Avila et al., 2013) to $2,134 \mathrm{mg} / 100 \mathrm{~g}$ oil in nuts of Mahan variety grown in northern Tunisia (Bouali et al., 2014). In this last study, the content of $\beta$-sitosterol decreased with pecan rippening; the same tendency was observed in nuts from Mahan, Moore and Burkett cultivars, but the lowest content of $\beta$-sitosterol found by these authors was of $872 \mathrm{mg} / 100 \mathrm{~g}$ oil (still considerably higher than values reported by other authors in nuts from other locations). A smaller variability in the content of $\beta$-sitosterol has been reported among commercial pecan nuts and oils available in the USA (91.4-234.3 mg/100g oil or $116.5-130.1 \mathrm{mg} / 100 \mathrm{~g} \mathrm{nut})$. (Fernandes et al., 2017) reported that $\beta$-sitosterol represented approximately $75 \%$ of the total desmethylsterols of pecan oil (they analyzed commercial oil and oil extracted from commercial pecan nuts, both available in Brazil) and, considering that their samples contained 1790-1750 mg total desmethylsterols per $\mathrm{kg}$ of oil, this would indicate approximately $133 \mathrm{mg} / 100 \mathrm{~g}$ oil.

A similar behavior is observed in the pattern of variation of the other major pecan phytosterols. $\Delta 5$-avenasterol is the second most abundant phytosterol, with concentrations ranging from 10.0 to $214.4 \mathrm{mg} / 100 \mathrm{~g}$ oil and a much smaller range reported in commercial nuts available in the USA (12.6-14.6 mg/100g nut). Nevertheless, this phytosterol did not decrease during pecan rippening as opposed to $\beta$-sitosterolcampesterol and stigmasterol(Bouali et al., 2014). Campesterol and stigmasterol have been reported to vary between $1.5-193.5$ and $0.3-100 \mathrm{mg} / 100 \mathrm{~g}$ oil, respectively; while variations among different studies carried out in commercial nuts from USA are much smaller (see Table 2). It is apparent that environmental conditions, combined with the specific cultivars grown on different locations may explain the differences in the content of phytosterols in pecan; however, to our knowledge, no systematic study of phytosterol content in different pecan cultivars or in the same cultivar grown in distant locations (with widely different environmental conditions), has been carried out.

Only three papers have reported the contents of phospholipids and sphingolipids in pecan and other nut oils (see references in Table 2). Phospho- and sphingolipids are minor oil components containing phosphate and one or two fatty acids linked to either a glycerol or a sphingosine backbone (although not al sphingolipids contain phosphate). Recent clinical and biological evidence has supported the concept that phospholipids have beneficial effects on plasma/liver lipid metabolism and atherosclerosis progress (Song et al., 2018); however, very little information exists on their abundance in nut oils. The total phospholipid content of pecan oil is $1.19 \%$, which is low in comparison with other tree nut oils (Song et al., 2018). The first studies that identified and quantified phospholipids in nuts indicated that phosphatidylcholine (PC) and phosphatidylserine (PS) were the most abundant phospholipids in pecan (Miraliakbari and Shahidi, 2008a; Miraliakbari and Shahidi, 2008b). However, the most recent work, where phospholipid profiles were characterized by hydrophilic interaction liquid chromatography (HILIC) and hybrid ion trap-time of flight mass spectrometry (IT-TOF-MS), showed that phosphatidic acid (PA) and phosphatidylinositol (PI) were the major phospholipids in pecan oil (Song et al., 2018). This last study found no evidence for the presence of sphingolipids in pecan and other tree nut oils, although the previous papers had reported that these lipids could represent up to $0.55 \%$ of the total pecan oil. Further studies should characterize these lipids in different pecan cultivars and demonstrate their biological effect.

Polyphenols are plant antioxidants that contain at least one aromatic ring with one or more hydroxyl groups. According to this definition, tocopherols can be considered as polyphenols, however most plant polyphenols are much more hydrophilic than tocopherols since they do not contain long hydrophobic chains. Due to their mostly hydrophilic nature, polyphenols are concentrated in the non-lipid fraction of pecan nuts (deffated kernel fractions and non-edible by-products) and only low quantities can be found in 
the oil. Three studies have quantified total polyphenols in pecan oils extracted by different techniques from nuts acquired in different locations (see references in Table 2), however we are not aware of any work that has actually identified individual phenolic compounds in pecan oil. Total phenolic compounds expressed as gallic acid equivalents (GAE) range between 40 and $783 \mathrm{mg} \mathrm{GAE} /$ $\mathrm{kg}$ oil, depending strongly on the oil extraction technique and conditions. It is possible that most of these polyphenols are actually tocopherols, so a better form of expressing their content could be as tocopherol equivalents (TocE, (Miraliakbari and Shahidi, 2008a).

Finally, pecan oil also contains other lipid soluble phytochemicals like carotenoids and squalene, although very limited information exists on their presence, probably due to the low content in pecan, in comparison with other dietary sources. The USDA reports $29 \mu \mathrm{g}$ of $\beta$-carotene per $100 \mathrm{~g}$ of kernel and $17 \mu \mathrm{g}$ per 100 $\mathrm{g}$ of kernel of lutein + zeaxanthin(USDA, 2016), although another study reported undetectable levels of $\beta$-carotene and lutein in commercial pecans purchased in Europe (Kornsteiner et al., 2006).Bouali et al. (2013) found that lutein and zeaxanthin levels decreased gradually (from 20 to 150 times) in pecan oil as fruit ripening advanced from 20 to 27 weeks after flowering. Squalene is a 30-carbon terpenic hydrocarbon, precursor of phytosterols in plants and cholesterol in animals. Squalene is reported to have antioxidant activity and other health benefits (Derewiaka et al., 2014; Fernandes et al., 2017) and its content in pecan has shown a narrow range (from 208.2 to $320 \mathrm{mg} / \mathrm{kg}$ oil) in commercial oil and oil extracted from commercial nuts available in Poland and Brazil (Derewiaka et al., 2014; Fernandes et al., 2017).

\section{Hydrophylic phytochemicals in pecan: polyphenols in kernel and by-products}

Plant-derived polyphenols, also known as polyphenolic compounds, are plant secondary metabolites synthesized through the phenylpropanoid metabolic pathway. They can be broadly divided in flavonoids, which possess a phenyl benzopyran skeleton, and non-flavonoids, of which phenolic acids are the most abundant. Flavonoids can be further divided in families, according to the oxidation and unsaturation of the pyran ring; flavonols and flavan-3-ols are the two flavonoid families most abundant in plant foods. Phenolic acids can also be divided in hydroxybenzoic and hydroxycinnamic acids and both flavonoids and phenolic acids can be found in nature forming glycosides (linked to monosacharides or disacharides), esthers (linked to quinic and other organic acids) and more complex structures such as tannins. Condensed tannins or proanthocyanidins are flavan-3-ol oligomers and polymers while hydrolysable tannins consist of multiple units of gallic acid or hexahydroxydiphenoyl acid (which in aqueous solution spontaneously lactonizes into ellagic acid) esterified to a sugar core. Polyphenols are potent antioxidants at low concentrations, acting as free radical scavengers and sometimes as metal chelators; at high concentrations they may behave as prooxidants(Shahidi and Ambigaipalan, 2015). Polyphenols possess numerous biological effects many of them related to their antioxidant/prooxidant characteristics, but they are also known to regulate gene expression and protein activity through other mechanisms (Sauceda et al., 2018).

Polyphenols are ubiquitously distributed in most plant tissues and, due to the presence of multiple hydroxyl groups are soluble in polar solvents. Therefore, polyphenols are found mostly in the deffated kernel fractions of pecan and are especially concentrated in some pecan by-products such as its hard shell. Phenolic extracts of plant materials are always a mixture of different classes of poly- phenols that are soluble in the solvent system used (Nackz and Shahidi, 2004); so the chosen solvent is key to the type and content of individual polyphenols that can be found in different extracts of similar samples. Individual compounds must be identified and quantified after HPLC separation and the most recent studies have used mass spectrometry and tandem mass spectrometry to achieve identification of numerous individual polyphenols for which no commercial standards exist. However, simple colorimetric techniques can also be used as a good approach to determine total polyphenols, total flavonoids and total proanthocyanidins (condensed tannins) of different plant extracts.

Total polyphenols have been determined in pecan kernel and by-products (nutshell, leave and cake) by the Folin-Ciocalteu assay (Table 3). Most studies have reported their content in $\mathrm{mg}$ or $\mathrm{g}$ of gallic acid equivalents (GAE) per gram or 100 grams of raw material. In kernel, most studies have used acetone/water as extraction solvent and total polyphenols range from 829 to 2,016 mg GAE/100 g of whole kernel. A study that used methanol/ chloroform $/ 1 \% \mathrm{NaCl}(1: 1: 0.5, \mathrm{v} / \mathrm{v} / \mathrm{v})$ found slightly higher values (1,925-2,313 mg GAE/100g, (Flores-Córdova et al., 2017); while a work that extracted bound polyphenols after basic hydrolysis of the sample (Yang, 2009) found low levels of this type of phenolic compounds in pecan kernel (236.6 mg GAE/100g). Differences among samples may be due to cultivar, location, environmental or extraction conditions; anyhow the content of total polyphenols in pecan kernel is high in comparison with other foods, placing pecans among the 50 richest dietary sources of polyphenols (Bolling et al., 2011). Other authors have used chlorogenic or ellagic acids as standards for total polyphenols. Values reported as chlorogenic acid equivalents (CAE) are considerably higher than those reported as GAE $(6,200-10,600 \mathrm{mg}$ CAE per $100 \mathrm{~g}$ of deffated kernel for different cultivars) while values reported as EAE (ellagic acid equivalents) are much lower (1.82-2.62 mg EAE per $100 \mathrm{~g}$ of whole kernel for different cultivars). In by-products, nutshells contain the highest amounts of total polyphenols, around ten times more than kernels, with values up to $59.1 \mathrm{~g}$ GAE per $100 \mathrm{~g}$ of nutshell (that is 59.1\%); while leaves and pecan cakes (the by-products of the commercial oil industry) show low values, even lower than those of whole kernels (2.1-690 mg GAE per $100 \mathrm{~g}$ of byproduct). (do Prado et al., 2014) extracted polyphenolic compounds from nutshells using different solvents and techniques: infusion (in water), infusion followed by spray drying, solvent extraction with ethanol at room temperature and SFE with absolute ethanol as co-solvent. They found the highest content of total polyphenols in the extract obtained by infusion followed by spray drying (591 mg GAE per g of nutshell), but this was because the spray drying process concentrated the solids. In contrast, SFE showed the lowest recovery of total solids and polyphenols, even at the highest pressure tested (0.3-9.3 mg GAE per $\mathrm{g}$ of nutshell) showing the unsuitability of this technique to extract polyphenols from nutshells. The extracts obtained by infusion and ethanol extraction at room temperature showed similar levels of polyphenols, also comparable with other studies which indicate a content of total polyphenols that range between 1.4 and $25 \mathrm{~g} \mathrm{GAE}$ per $100 \mathrm{~g}$ of nutshell (that is 14 to $250 \mathrm{mg} \mathrm{GAE} / \mathrm{g}$ ). Variation in the content of total polyphenols in pecan nutshells is mainly due to differences in cultivar (Hawary et al., 2016; Villarreal-Lozoya et al., 2007) although the growing location and extraction conditions also have an effect (de la Rosa et al., 2011; de la Rosa et al., 2014; do Prado et al., 2014).

Some studies have quantified total flavonoids by their complexation with aluminum chloride, which can be assessed spectrophometrically and expressed, usually, as catechin or quercetin equivalents (CE or QE, respectively). The content of total flavonoids in 
Table 3. Total polyphenols, flavonoids and proanthocyanidins in pecan kernels and byproducts

\begin{tabular}{|c|c|c|c|c|}
\hline Plant part & $\begin{array}{l}\text { Content in } 100 \\
\text { g of sample }\end{array}$ & Extraction solvent & Comments on the samples & Reference \\
\hline \multicolumn{5}{|c|}{ Total polyphenols (Folin-Ciocalteu assay) } \\
\hline Kernel & $2,016 \mathrm{mg} \mathrm{GAE}$ & $\begin{array}{l}\text { acetone/water/acetic } \\
\text { acid (70/29.5/0.5) }\end{array}$ & Commercial sample & Wu et al., 2004 \\
\hline Kernel & 1,022-1,444 mg GAE & $75 \%$ acetone with $\mathrm{Na}_{2} \mathrm{~S}_{2} \mathrm{O}_{5}$ & Commercial samples & Kornsteiner et al., 2006 \\
\hline Kernel & $6,200-10,600 \mathrm{mg} \mathrm{CAE}^{1}$ & $70 \%$ acetone & Different cultivars & $\begin{array}{l}\text { Villarreal-Lozoya } \\
\text { et al., } 2007\end{array}$ \\
\hline Kernel & $8,200-10,400 \mathrm{mg} \mathrm{CAE}^{1}$ & $70 \%$ acetone & $\begin{array}{l}\text { Different cultivars and } \\
\text { postharvest treatments }\end{array}$ & $\begin{array}{l}\text { Villarreal-Lozoya } \\
\text { et al., } 2009\end{array}$ \\
\hline Kernel & $1,227.3 \mathrm{mg} \mathrm{GAE}$ & $80 \%$ acetone & Commercial sample, free phenolics & Yang et al., 2009 \\
\hline Kernel & $236.6 \mathrm{mg}$ GAE & $\begin{array}{l}\text { Methanol/ethyl acetate } \\
\text { after basic hydrolysis }\end{array}$ & $\begin{array}{l}\text { Commercial sample, } \\
\text { bound phenolics }\end{array}$ & Yang et al., 2009 \\
\hline Kernel & $1,170-1,250 \mathrm{mg}$ GAE & $80 \%$ acetone & Different locations & de la Rosa et al., 2011 \\
\hline Kernel & 829-959 mg GAE & $80 \%$ acetone & Different locations & de la Rosa et al., 2014 \\
\hline Kernel & $1.82-2.62 \mathrm{mg} E A E$ & $\begin{array}{l}\text { acetone/water/acetic } \\
\text { acid (70/29.5/0.5) }\end{array}$ & Different cultivars & Robbins et al., 2015 \\
\hline Kernel & 1,925-2,313 mg GAE & $\begin{array}{l}\text { methanol/chloroform/1\% } \\
\mathrm{NaCl}(1 / 1 / 0.5)\end{array}$ & Different cultivars & Flores-Cordova et al., 2017 \\
\hline Nutshell & $29-63$ g CAE & $70 \%$ acetone & Different cultivars & $\begin{array}{l}\text { Villarreal-Lozoya } \\
\text { et al., } 2007\end{array}$ \\
\hline Nutshell & 11.7-16.7 g GAE & water & Different batches & do Prado et al., 2009 \\
\hline Nutshell & $19.1 \mathrm{~g} \mathrm{GAE}$ & no information & no information & Medina et al., 2010 \\
\hline Nutshell & $6.5-9.2$ g GAE & $80 \%$ acetone & Different locations & de la Rosa et al., 2011 \\
\hline Nutshell & 19.2 g GAE & water & no information & Reckziegel et al., 2011 \\
\hline Nutshell & 9.4-18.1 g GAE & water & Different years and cultivars & do Prado et al., 2013 \\
\hline Nutshell & $19.2 \mathrm{~g} \mathrm{GAE}$ & water & Commercial sample & Müller et al., 2013 \\
\hline Nutshell & $12.8 \mathrm{~g} \mathrm{GAE}$ & water & Barton variety & Porto et al., 2013 \\
\hline Nutshell & $2.4-5.4$ g GAE & $80 \%$ acetone & Different locations & de la Rosa et al., 2014 \\
\hline Nutshell & $0.03-59.1$ g GAE & $\begin{array}{l}\text { water, ethanol, } \\
\text { supercritical } \mathrm{CO}_{2}\end{array}$ & Different extraction conditions & do Prado et al., 2014 \\
\hline Nutshell & 1.4-25 mg GAE & ethanol & Different cultivars & Hawary et al., 2016 \\
\hline Nutshell & $42.6 \mathrm{~g}$ GAE & water & Barton variety & Hilbig et al., 2016 \\
\hline Nutshell & $14.5-17.0$ g GAE & $\begin{array}{l}\text { methanol/chloroform/1\% } \\
\mathrm{NaCl}(1 / 1 / 0.5)\end{array}$ & Different cultivars & Flores-Cordova et al., 2017 \\
\hline Leave & 3.2-98 mg GAE & ethanol & Different cultivars & Hawary et al., 2016 \\
\hline Kernel cake & $690 \mathrm{mg}$ GAE & $80 \%$ ethanol & Industrial byproducts & Sarkis et al., 2014 \\
\hline Kernel cake & $2.2-7.1 \mathrm{mg} \mathrm{GAE}$ & $\begin{array}{l}\text { ethanol, acetone, } \\
\text { supercritical } \mathrm{CO}_{2}\end{array}$ & Different extraction conditions & Salvador et al., 2016 \\
\hline \multicolumn{5}{|c|}{ Total flavonoids ( $\mathrm{AlCl}_{3}$ assay) } \\
\hline Kernel & $639.3 \mathrm{mg} \mathrm{CE}$ & $80 \%$ acetone & Commercial sample, free phenolics & Yang et al., 2009 \\
\hline Kernel & $65.4 \mathrm{mg} \mathrm{CE}$ & $\begin{array}{l}\text { Methanol/ethyl acetate } \\
\text { after basic hydrolysis }\end{array}$ & $\begin{array}{l}\text { Commercial sample, } \\
\text { bound phenolics }\end{array}$ & Yang et al., 2009 \\
\hline Kernel & 580-640 mg CE & $80 \%$ acetone & Different locations & de la Rosa et al., 2011 \\
\hline Kernel & 345-397 mg CE & $80 \%$ acetone & Different locations & de la Rosa et al., 2014 \\
\hline Nutshell & $2.6-3.6$ g CE & $80 \%$ acetone & Different locations & de la Rosa et al., 2011 \\
\hline
\end{tabular}


Table 3. Total polyphenols, flavonoids and proanthocyanidins in pecan kernels and byproducts - (continued)

\begin{tabular}{|c|c|c|c|c|}
\hline Plant part & $\begin{array}{l}\text { Content in } 100 \\
\mathrm{~g} \text { of sample }\end{array}$ & Extraction solvent & Comments on the samples & Reference \\
\hline Nutshell & $1.6 \mathrm{~g} \mathrm{CE}$ & water & Barton variety & Porto et al., 2013 \\
\hline Nutshell & $1.6-3.2 \mathrm{~g} \mathrm{CE}$ & $80 \%$ acetone & Different locations & de la Rosa et al., 2014 \\
\hline Nutshell & 1.2-6.7 mg QE & ethanol & Different cultivars & Hawary et al., 2016 \\
\hline Nutshell & $9-30 \mathrm{mg}^{2}$ & methanol & Different cultivars & Hawary et al., 2016 \\
\hline Leave & 13-21 mg QE & ethanol & Different cultivars & Hawary et al., 2016 \\
\hline Leave & $107-173 \mathrm{mg}^{2}$ & methanol & Different cultivars & Hawary et al., 2016 \\
\hline Kernel cake & $690 \mathrm{mg}$ CE & $80 \%$ ethanol & Industrial byproducts & Sarkis et al., 2014 \\
\hline \multicolumn{5}{|c|}{ Total proanthocyanidins (Vanillin-HCl assay) } \\
\hline Kernel & $2,300-4,700 \mathrm{mg} \mathrm{CE}^{1}$ & $70 \%$ acetone & Different cultivars & $\begin{array}{l}\text { Villarreal-Lozoya } \\
\text { et al., } 2007\end{array}$ \\
\hline Kernel & $2,300-5,300 \mathrm{mg} \mathrm{CE}^{1}$ & $70 \%$ acetone & $\begin{array}{l}\text { Different cultivars and } \\
\text { postharvest treatments }\end{array}$ & $\begin{array}{l}\text { Villarreal-Lozoya } \\
\text { et al., } 2009\end{array}$ \\
\hline Kernel & $2,030-2,670 \mathrm{mg}$ CE & $80 \%$ acetone & Different locations & de la Rosa et al., 2011 \\
\hline Kernel & 2,828-3,950 mg CE & $80 \%$ acetone & Different locations & de la Rosa et al., 2014 \\
\hline Kernel & 420-655 mg PBE 3 & $\begin{array}{l}\text { acetone/water/acetic } \\
\text { acid (70/29.5/0.5) }\end{array}$ & Different cultivars & Robbins et al., 2015 \\
\hline Kernel & 2,181-2,322 mg CE & $\begin{array}{l}\text { methanol/chloroform/1\% } \\
\mathrm{NaCl}(1 / 1 / 0.5)\end{array}$ & Different cultivars & Flores-Cordova et al., 2017 \\
\hline Nutshell & $38.8-87.6$ g CE & $70 \%$ acetone & Different cultivars & $\begin{array}{l}\text { Villarreal-Lozoya } \\
\text { et al., } 2007\end{array}$ \\
\hline Nutshell & $2.6-4.8 \mathrm{~g}$ CE & water & Different cultivars & $\begin{array}{l}\text { Villarreal-Lozoya } \\
\text { et al., } 2007\end{array}$ \\
\hline Nutshell & 3.5-4.8 g CE & water & Different batches & do Prado et al., 2009 \\
\hline Nutshell & $14.46 \mathrm{~g} \mathrm{CE}$ & no information & no information & Medina et al., 2010 \\
\hline Nutshell & 31.6-46.4 g CE & $80 \%$ acetone & Different locations & de la Rosa et al., 2011 \\
\hline Nutshell & $3.6-4.9$ g CE & water & Different years and cultivars & do Prado, 2013 \\
\hline Nutshell & $5.8 \mathrm{~g} \mathrm{CE}$ & water & no information & Reckziegel et al., 2011 \\
\hline Nutshell & $5.8 \mathrm{~g} \mathrm{CE}$ & water & Commercial sample & Müller et al., 2013 \\
\hline Nutshell & $4.7 \mathrm{~g} \mathrm{CE}$ & water & Barton variety & Porto et al., 2013 \\
\hline Nutshell & $28.2-70.0 \mathrm{~g}$ CE & $80 \%$ acetone & Different locations & de la Rosa et al., 2014 \\
\hline Nutshell & $0.05-41.2 \mathrm{~g}$ CE & $\begin{array}{l}\text { water, ethanol, } \\
\text { supercritical } \mathrm{CO}_{2}\end{array}$ & Different extraction conditions & do Prado et al., 2014 \\
\hline Nutshell & $43.2-52.8$ g CE & $\begin{array}{l}\text { methanol/chloroform/1\% } \\
\mathrm{NaCl}(1 / 1 / 0.5)\end{array}$ & Different cultivars & Flores-Cordova et al., 2017 \\
\hline Kernel cake & 16.5-17.5 mg CE & $80 \%$ ethanol & Industrial byproducts & Sarkis et al., 2014 \\
\hline Kernel cake & 1.5-31.5 mg CE & ethanol, acetone & Different extraction conditions & Salvador et al., 2016 \\
\hline \multicolumn{5}{|c|}{ Total phenolic acids (HPLC) } \\
\hline Nutshell & $130-5,150 \mathrm{mg}$ & methanol & Different cultivars & Hawary et al., 2016 \\
\hline Leave & 264-604 mg & methanol & Different cultivars & Hawary et al., 2016 \\
\hline
\end{tabular}

Abreviations/GAE, gallic acid equivalents; $C A E$, chlorogenic acid equivalents; $E A E$, ellagic acid equivalents; $C E$, catechin equivalents; $Q E$, quercetin equivalents; $P B E$, procyanidin $B 2$ equivalents. Notes $/{ }^{1}$ reported in $100 \mathrm{~g}$ of deffated kernel; ${ }^{2}$ quantified by HPLC; ${ }^{3}$ quantified by the DMAC assay.

pecan kernel has been reported between 345 and $640 \mathrm{mg} \mathrm{CE} / 100 \mathrm{~g}$ of whole kernel, with lower amounts of bound forms $(65.4 \mathrm{mg}$ $\mathrm{CE} / 100 \mathrm{~g})$. Around five times more total flavonoids have been re- ported in pecan nutshells (1.6-3.6 g CE/100 g of nutshell).Hawary et al. (2016) determined total flavonoids, expressed as QE, in ethanol extracts of pecan nutshells and leaves and found higher 
content in the leaves. These authors also calculated the total flavonoid content of leaves and nutshells as the sum of all individual flavonoids quantified by HPLC in methanol extracts of both parts of the plant; they confirmed the higher flavonoid content of the leaves and found that total flavonoids quantified by HPLC in methanol extracts were higher than those determined as quercetin equivalents in ethanol extracts. Finally the total flavonoid content of kernel cakes, residues obtained after oil extraction (Sarkis et al., 2014), is very similar to the content of whole kernels, suggesting that flavonoids are not lost in the oil extraction process.

Total proanthocyanidins or condensed tannins can be quantified by several colorimetric assays, the most common of which is the vanillin- $\mathrm{HCl}$ assay. Proanthocyanidins are monomers, oligomers and polymers of catechin and other flavan-3-ols, so they are usually expressed as CE. Using this quantification technique in acetone extracts, pecan kernels showed proanthocyanidin contents from 2,030 to $3,950 \mathrm{mg}$ CE per 100 grams of whole kernel or 2,300 to $5,300 \mathrm{mg}$ CE per 100 grams of defatted kernel. Similar contents have been reported using methanol:chloroform extraction. These are very high values $(2-4 \%$ proanthocyanidin content in whole kernel); however, the vanillin- $\mathrm{HCl}$ assay is sensitive to the degree of polymerization of the molecule, so their content is sometimes overestimated in samples containing polymers (de la Rosa et al., 2014). Robbins et al. (2015)quantified total proanthocyanidins in acidified acetone kernel extracts, using a different colorimetric technique (the DMAC assay) and a dimer (procyanidin B2, PB) instead of a monomer as standard; they obtained values from 420 to $655 \mathrm{mg}$ PB equivalents per $100 \mathrm{~g}$ of whole kernel. In any case it is apparent that polymeric or oligomericproanthocyanidins are major components of the kernel acetone extracts and major polyphenolic compounds present in this nut. Total proanthocyanidins are even more abundant in the nutshells (more than ten times higher than in kernels), although their recovery is strongly dependent on the solvent used for extraction. Aqueous acetone is the solvent that allows the highest yields (28.2 to $87.6 \mathrm{~g} \mathrm{CE}$ per $100 \mathrm{~g}$ of nutshell) and the large variation among samples is due to their cultivar and growing location. Extraction with other solvents (methanol/chloroform or ethanol) shows similar results (41.2 to $52.8 \mathrm{~g} \mathrm{CE}$ per 100 $\mathrm{g}$ of nutshell) while water extracts show much lower recoveries, yielding proanthocyanidin contents of nutshells similar to those of kernels (2.6 to $5.8 \mathrm{~g} \mathrm{CE}$ per $100 \mathrm{~g}$ of nutshell). It is important to consider the major contribution of proanthocyanidins to the total polyphenolic content of pecan kernels and nutshells, although in the water extracts of nutshells other type of polyphenols must be predominant over proanthocyanidins. Low proanthocyanidin contents have been reported in kernel cakes (1.5-31.5 mg CE per 100 $\mathrm{g}$ of byproduct). Although the highest values were obtained by using acetone as extraction solvent (Salvador et al., 2016), they are still much lower than the content in whole kernel, suggesting that proanthocyanidins may be somehow lost during commercial oil extraction.

Hawary et al. (2016) determined the content of total phenolic acids of leaves and nutshells as the sum of all individual compounds quantified by HPLC in methanol extracts of both parts of the plant. They found that, contrary to flavonoids, phenolic acids were lower in the leaves than in the nutshells.

\subsection{Individual polyphenols in kernel}

Pecan kernels are rich sources of polyphenols; the most abundant are probably proanthocyanidins (flavan-3-ol oligomers and polymers), although they also contain high quantities of phenolic acids (which can be found free, as simple derivatives or as hydrolys- able tannins) and other non-polymerized flavonoids. Most studies aimed at the characterization of the polyphenolic profile of pecan kernel have been carried out during the last ten years using HPLC, and those that have identified the highest numbers of individual compounds have had to depend on MS or MS/MS for their identification. Most of the identified polyphenols belong to the classes of hydroxybenzoic acid derivatives, flavan-3-ol monomers and oligomers (Table 4). Although many of the individual compounds have been also quantified, most values are reported as $\mu \mathrm{g}$ per gram of extract, although others are reported per gram of whole kernel, so comparisons among different studies are difficult in most cases.

Among hydroxybenzoic acids, $p$-hydroxybenzoic, gentisic, protocatechuic, vanillic, and syringic acids have been reported, mostly in hydrolyzed extracts, suggesting that they could be originally present as glycosilated or other derivatives; actually a protocatechuichexoside has been identified by its MS spectrum (Robbins et al., 2014). The most common and abundant hydroxybenzoic acids in pecan kernel are gallic (Figure 2a) and ellagic (Figure 2b) acids and many ellagic acid derivatives (small ellagitannins). Gallic and ellagic acids have sometimes been found as free acids in crude acetone extracts, although their concentration is lower than in acid or basic hydrolyzed extracts. Ellagic acid content is usually higher than that of gallic acid, although one study found a high content of free gallic acid and no ellagic acid in a $60 \%$ metanol extract (Juhaimi et al., 2017). This could be due to the extraction solvent since all the other studies have been carried out in acetone extracts.

The major ellagic acid derivatives described in pecan kernel are valoneic acid dilactone (Figure 2c) and several isomers of ellagic acid pentosides and hexosides, methylated and galloylated derivatives and their glycosides (Figure 2d), hexahydroxydiphenic (HHDP) hexosides and galloylated HHDP hexosides (Figure 2e). Valoneic acid dilactone is the most commonly found ellagitannin, and the most abundant compound (after free ellagic acid) in pecan kernel acetone extracts (Gong and Pegg, 2017). It has been detected in acid-hydrolyzed extracts (de la Rosa et al., 2011) and in the low molecular weight fractions obtained by separation through Sephadex LH-20 column, where it has been found as water adduct (Robbins et al., 2014). The content of valoneic acid dilactone is affected by cultivar and is increased by acid hydrolysis of the extracts (Robbins et al., 2015). The other ellagic acid derivatives have been only tentatively identified by HPLC-MS, and since several isomers co-exist in the same extracts, the exact structures of each isomer are not known. The presence of HHDP derivatives is important since it could indicate the existence of higher molecular weight ellagitannins.

Few hydroxycinnamic acids have been identified in pecan kernel. Free caffeic acid, caffeic acid hexosides and sinapoylquinic acid have been identified in acetone extracts, while $p$-coumaric and ferullic acids have been found in methanol extracts.

Among flavonoids, flavan-3-ols are the most important. Monomeric flavan-3-ols include catechin(Figure 2f) and epicatechin, although catechin is more common. Catechin has been quantified in methanol and acetone extracts and its contents range from 2.5-50 mg/100 g whole kernel. An (epi)catechinhexoside has been identified in acetone extracts after LH-20 fractionation, since its identification was carried out by HPLC-MS no distinction between it being a catechin or epicatechin derivative could be made. Epigallocatechin and epigallocatechin-3-galate have been found in etanolextracts; while, in acetone extracts(Robbins et al., 2014)tentatively identified(epi)gallocatechin-3-galate, (epi)gallocatechin, and three isomers of (epi)catechin-3-gallate.

Many types proanthocyanidin oligomers coexist in pecan kernel extracts so the exact identification of every individual structure is extremely difficult. All studies have used acetone extracts (70-80 


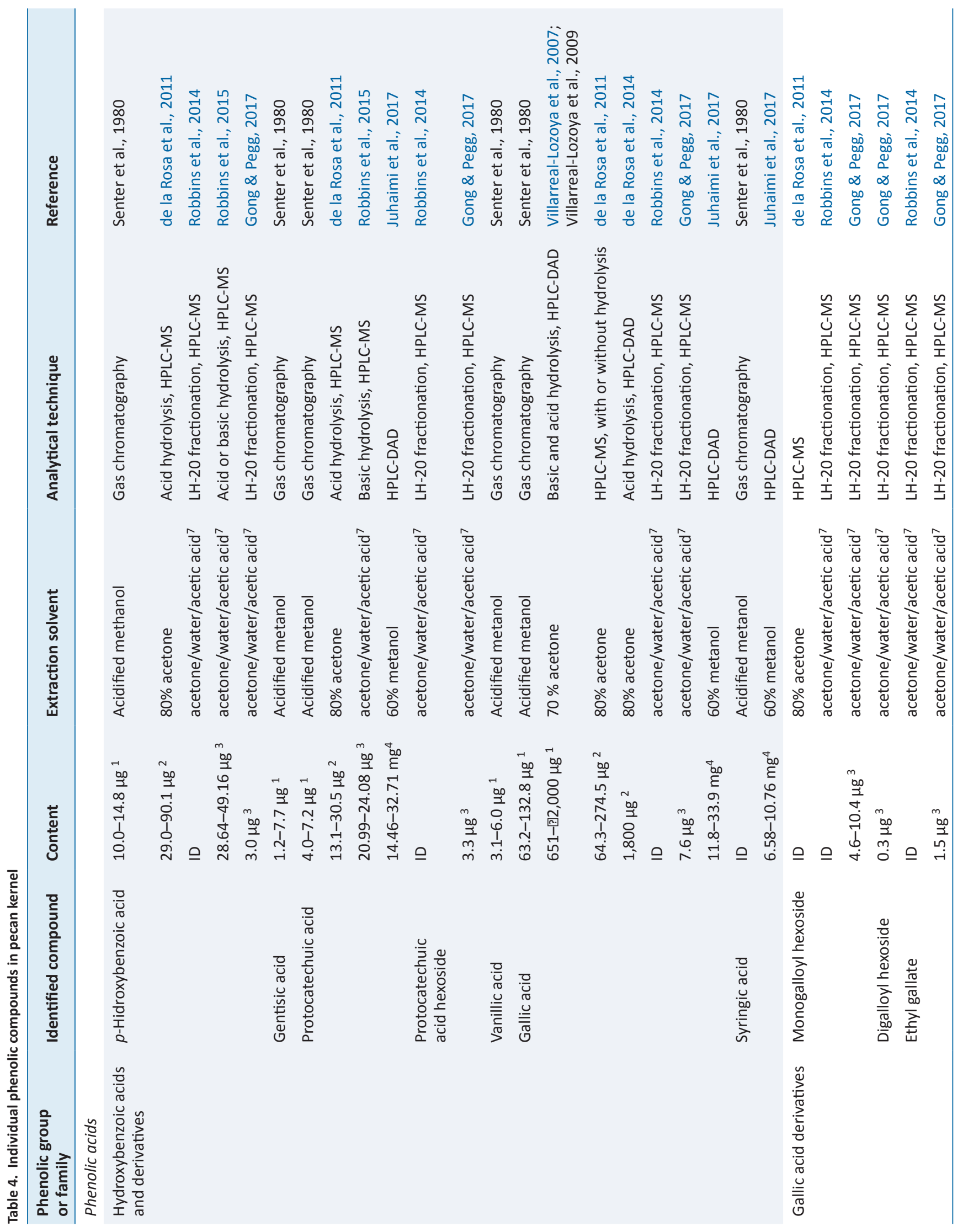




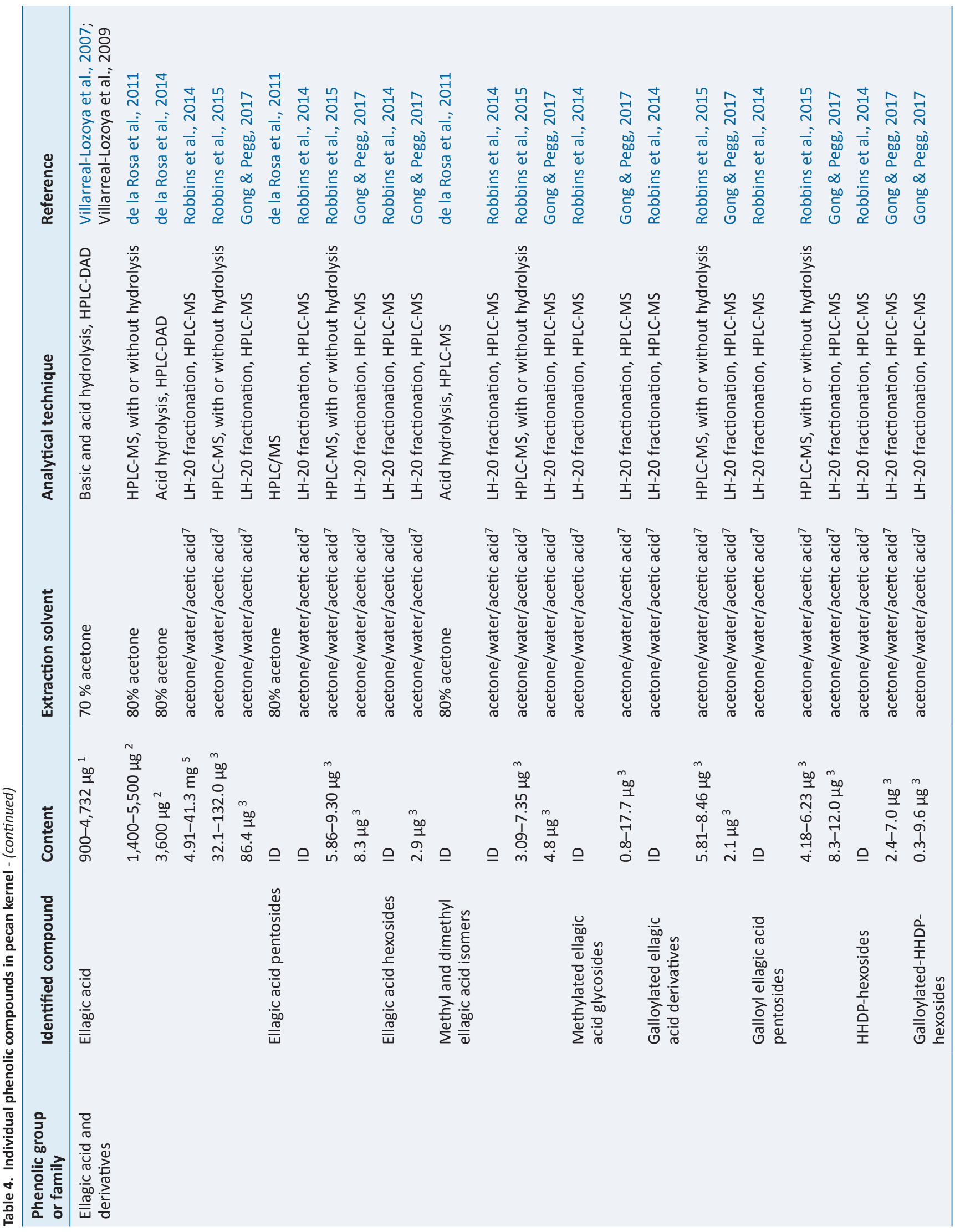




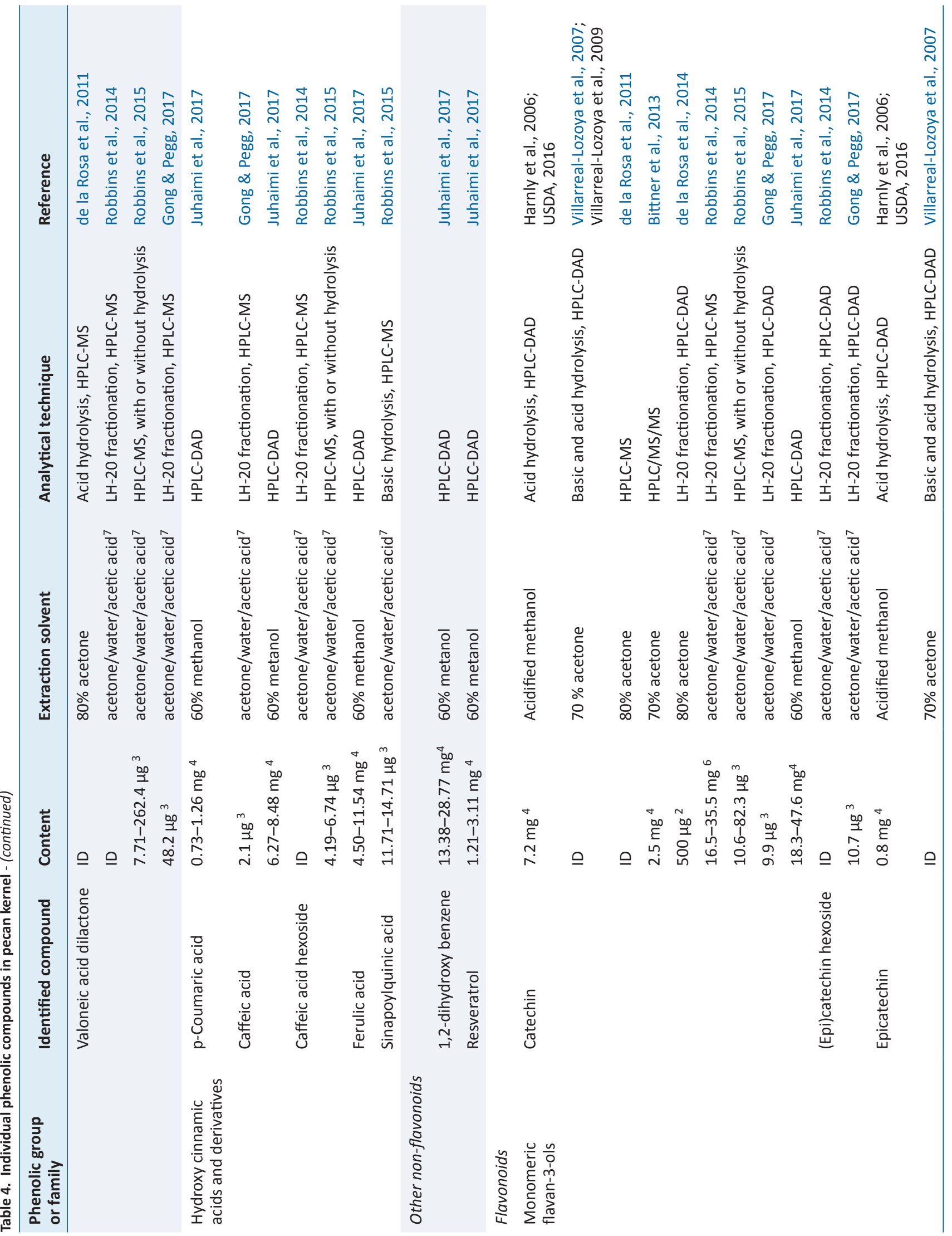




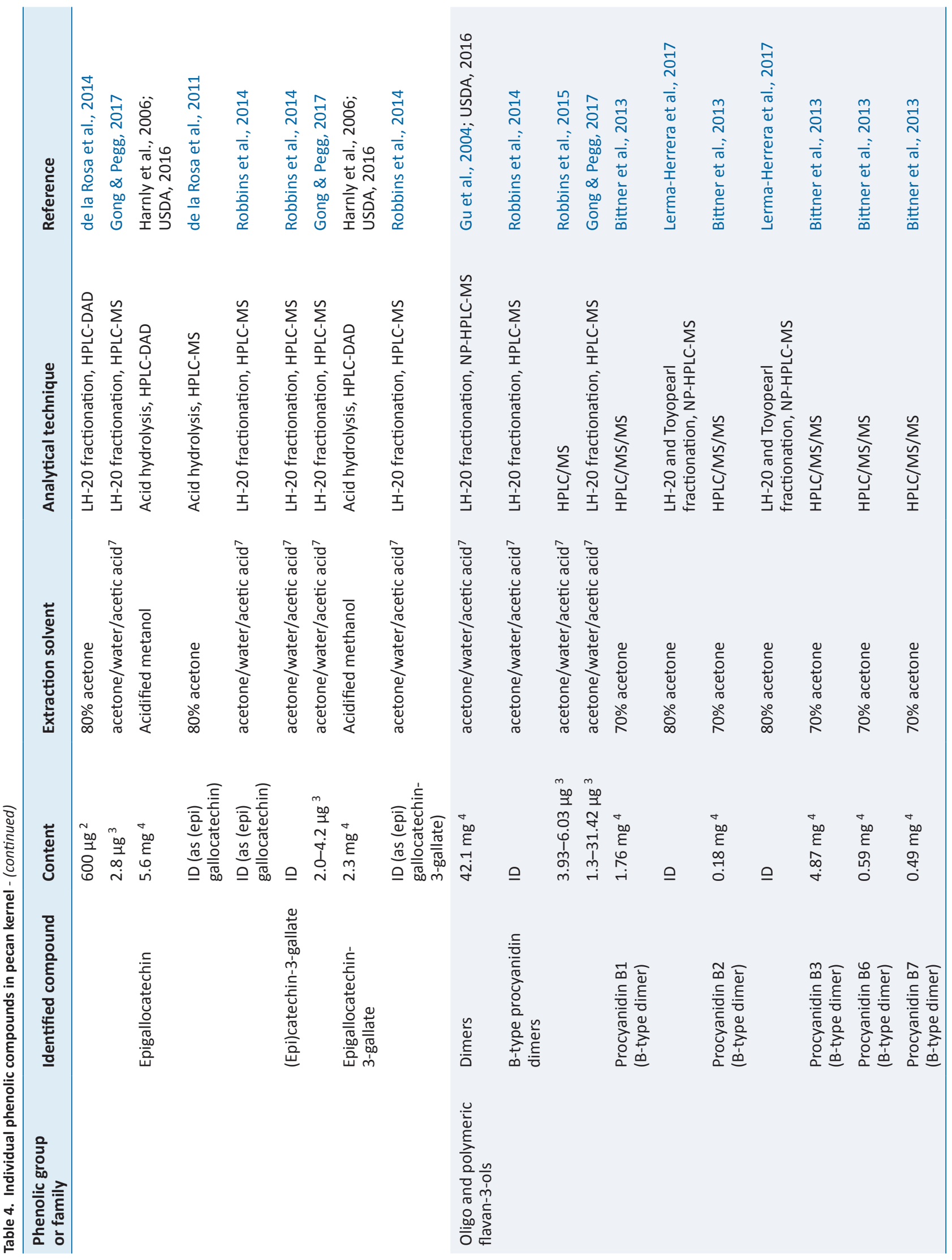




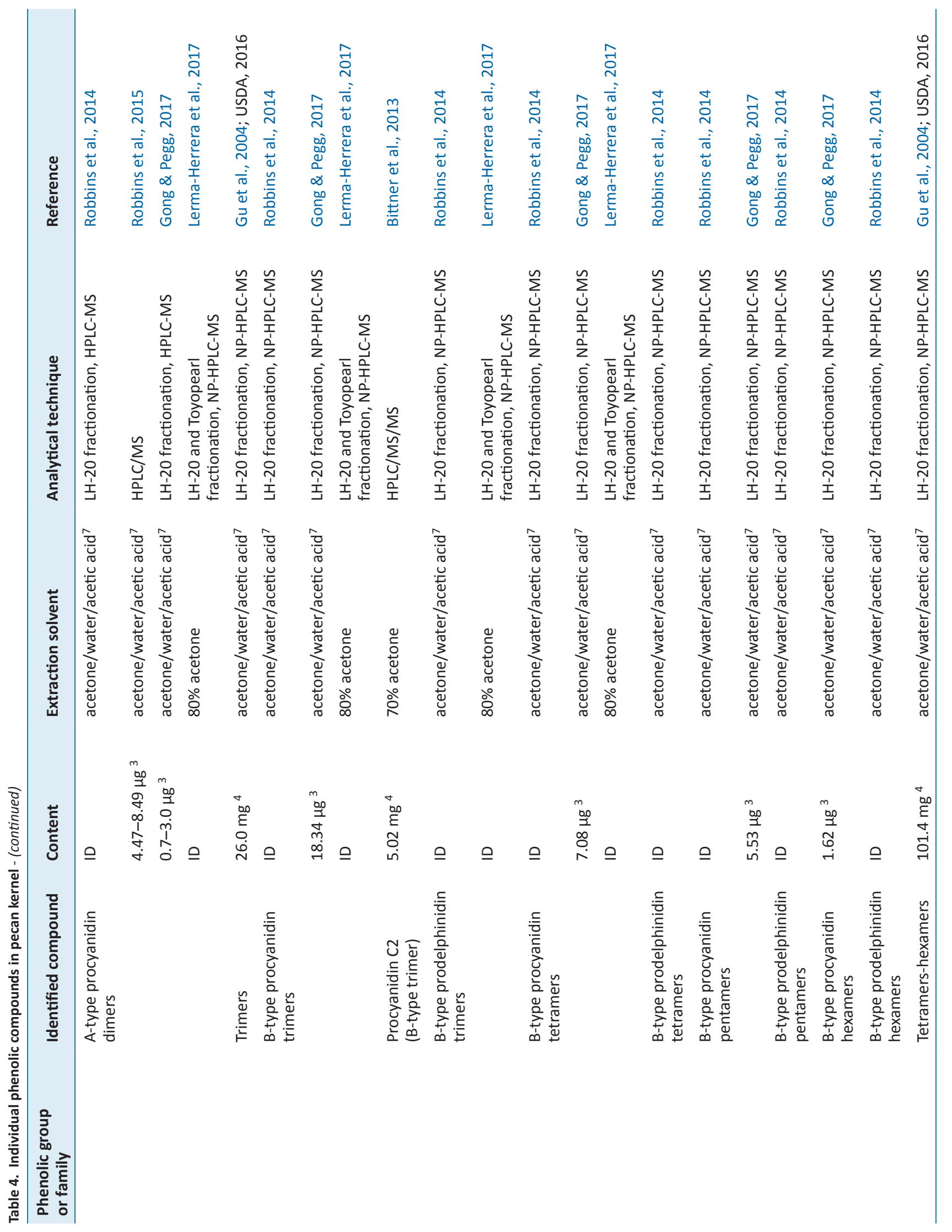




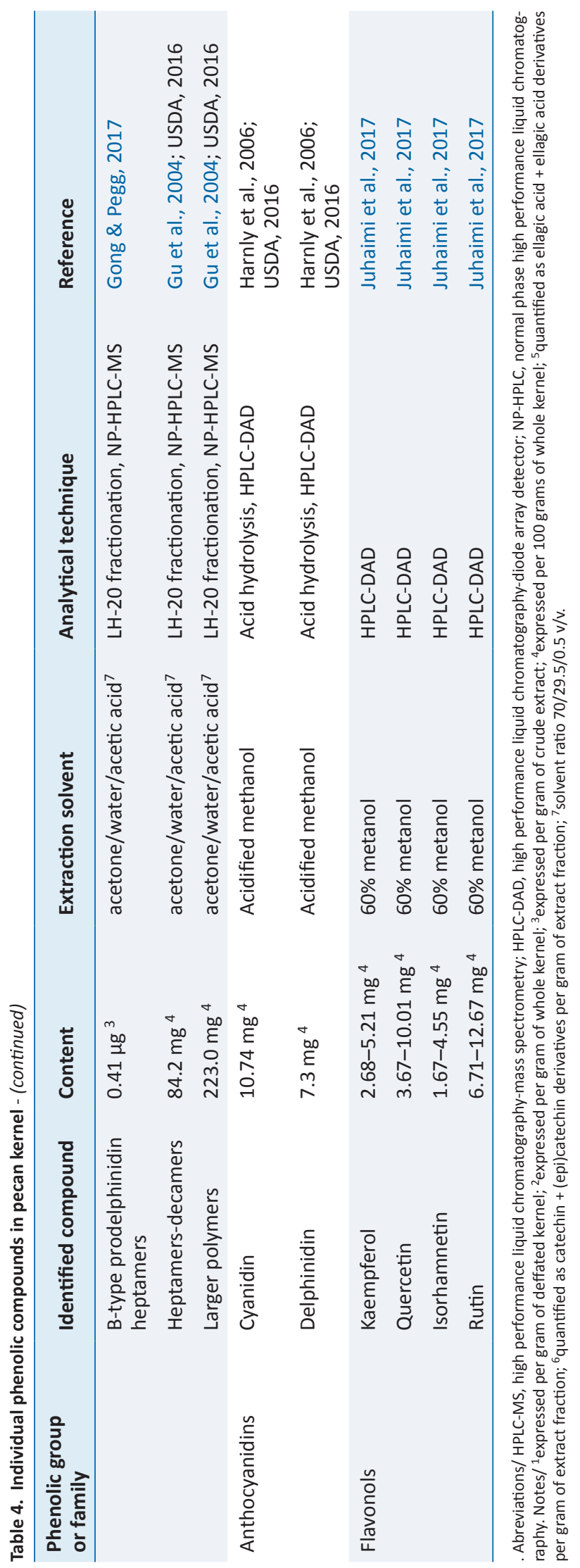

$\%$ acetone with or without acetic acid) and most have used sephadex LH-20 columns to separate the low and high molecular weight compounds, finding most proanthocyanidins in the high molecular weight fractions. The first studies only separated proanthocyanidins by their degree of polymerization and found from dimers to polymers larger than decamers, being the large polymers the most abundant forms (Gu et al., 2004). However, more recent studies have been unable to detect large polymers in pecan kernel acetone extracts and dimers have been found as the most abundant forms. Recent studies have also identified that some oligomers are composed only of catechin or epicatechin subunits (procyanidins) while others contain at least one gallocatechin or epigallocatechin unit (prodelphinidins). Procyanidins are more abundant than prodelphinidins and most are B-type procyanidins (they contain only one $\mathrm{C}-\mathrm{C}$ bond between monomers). Several authors have consistently found B-type procyanidin dimers to pentamers and A-type procyanidin dimers. B-type procyanidinhexamers have also been reported (Gong and Pegg, 2017). The most common prodelphinidins are trimers(Lerma-Herrera et al., 2017; Robbins et al., 2014), but tetramers to heptamers have also been reported (Gong and Pegg, 2017; Robbins et al., 2014). (Bittner et al., 2013) carried out a systematic study of identification and quantification of flavan3-ols (monomeric and oligomeric) in nuts in cereals using real standards and HPLC/MS/MS, they found 5 individual procyanidin B dimers (B1, B2, B3, B6 and B7) and one trimer (C2). Procyanidin B3 was the most abundant, followed by procyanidin B1 (Figure 2g). (Lerma-Herrera et al., 2017) also found procyanidins B1 and B2. Other types of flavonoids (anthocyanidins and flavonols) have been found only in methanol kernel extracts, not in acetone extracts.

\subsection{Individual polyphenols in by-products}

Phenolic acids, flavonoids and proanthocyanidins have been identified or quantified by HPLC, HPLC-MS (only in nutshell) or NMR studies of pecan by-products (Table 5). The most studied byproduct is nutshell, followed by leaves, and finally kernel cake and bark. Most results are reported as $\mathrm{mg} / \mathrm{g}$ sample, even though some studies report their results as $\mathrm{mg} / \mathrm{mL}$ or $\mathrm{mg} / \mathrm{g}$ extract.

The only study on the individual phenolic compounds on pecan bark was carried out by (Abdallah et al., 2011), who identified protocatechuic acid, quercetin and five methyl ethers of quercetin, including azaleatin and caryatin (Figure 2i), in ethanolic extracts. Identification and structure elucidation was achieved by NMR, after liquid-liquid extraction with different solvents, and fractionation with Sephadex LH-20. The three caryatin derivatives showed ether, sulfate or glucose in their structure. Interesting, no flavan3-ols were identified in the samples, even though they are the main flavonoids found in pecan kernel, nutshell, and leaves.

Different authors have evaluated the individual phenolic compounds in pecan leaves, using methanol, ethanol or water as solvents, and HPLC-DAD and NMR as identification techniques (Bottari et al., 2017; Gad et al., 2007; Hawary et al., 2016). Among non-flavonoids, hydroxybenzoic acid and derivatives, mainly ellagic and gallic acids, are the most abundant compounds, and higher phenolic content was observed when ethanol was used as solvent. Ellagic acid content ranged from 0.59 to $118.5 \mathrm{mg} / \mathrm{g}$ of leaves depending mainly on the extraction solvent. Gallic acid content varied from 0.08 to $87.3 \mathrm{mg} / \mathrm{g}$ of leaves, once again depending mainly on the solvent used. Other non-flavonoids found in lower content include protocatechuic acid, caffeic acid, ferulic acid and catechol. Among flavonoids, monomeric flavan-3-ols catechin (43.3 mg/g leaves) and epigallocatechin (17.3 mg/g leaves) 
<smiles>O=C(O)c1cc(O)c(O)c(O)c1</smiles>

(a)<smiles>O=c1oc2c(O)c(O)cc3c(=O)oc4c(O)c(O)cc1c4c23</smiles>

(b)<smiles>O=C(O)c1cc(O)c(O)c(O)c1Oc1cc2c(=O)oc3c(O)c(O)cc4c(=O)oc(c1O)c2c34</smiles>

(c)<smiles>O=C(O[C@H]1O[C@@H]2COC(=O)c3cc(O)c(O)c(O)c3-c3c(cc(O)c(O)c3O)C(=O)O[C@H]2[C@H](O)[C@@H]1O)c1cc(O)c(O)c(O)c1</smiles><smiles>Oc1cc(O)c2c(c1)O[C@H](c1ccc(O)c(O)c1)[C@H](O)C2</smiles><smiles>C[C@@H]1O[C@H](OC[C@H]2O[C@H](Oc3c(-c4ccc(O)c(O)c4)oc4cc(O)cc(O)c4c3=O)[C@H](O)[C@H](O)[C@H]2O)[C@H](O)[C@@H](O)[C@H]1O</smiles><smiles>COc1c(OC2OCC(O)C(O)C2O)cc2c(=O)oc3c(O)c(O)cc4c(=O)oc1c2c34</smiles><smiles>Oc1cc(O)c2c(c1)O[C@H](c1ccc(O)c(O)c1)[C@H](O)[C@H]2c1c(O)cc(O)c2c1O[C@H](c1ccc(O)c(O)c1)[C@H](O)C2</smiles>

(g)<smiles>COc1c(-c2ccc(O)c(O)c2)oc2cc(O)cc(OC)c2c1=O</smiles>

(i)

Figure 2. Chemical structures of common phytochemicals in pecan.

are the most abundant compounds, and contrary to non-flavonoid compounds, water extract showed higher content than ethanol or methanol extracts. Flavonols such as quercetin and derivatives (rutin, Figure 2h), flavones such as hesperetin (and its 7-O-glucoside derivative, hesperidin) and flavanones such as naringenin have also been reported in lower content.

There is only one published report regarding the identification of individual phenolic compounds in kernel cake, using $80 \%$ ethanol as solvent, and the identification of phenolic compounds was carried out by HPLC-DAD, after an acid hydrolysis(Sarkis et al., 2014). Authors identified hydroxybenzoic acids (ellagic and gallic acids) and monomeric flavan-3-ols (catechin and epicatechin). These compounds are also the most commonly found in whole pecan kernel (see previous section).

Most of the research on identification and quantification of individual phenolic compounds of pecan by-products has been done on pecan nutshell. Water, methanol, ethanol and acetone are the most common extraction solvents, and samples have been analyzed with or without previous acid hydrolysis. Gallic acid is the hydroxybenzoic acid showing the highest content, its content varied largely from $2.3 \mathrm{mg} / \mathrm{g}$ of nutshell when extracted with $80 \%$ acetone with acidic hydrolysis (de la Rosa et al., 2014) to $829 \mathrm{mg} / \mathrm{g}$ when extracted with ethanol (do Prado et al., 2014). $p$-Hydroxybenzoic acid is the second hydroxybenzoic acid found with concentrations as high as $148.9 \mathrm{mg} / \mathrm{g}$ when extracted with ethanol (do Prado et al., 2014). Contrary to leaves and kernels, ellagic acid content is much lower than gallic acid. Even though hydrolysable tannins have not been quantified in pecan by-products, the presence of these two hydroxybenzoic acids (ellagic and gallic acids) may indicate that hydrolysable tannins are present in these by-products. A high concentration of chlorogenic acid $(233.4 \mathrm{mg} / \mathrm{g}$ of extract) has been reported in a water extract (do Prado et al., 2014). Other hydroxycinnamic acid derivatives found in nutshell include caffeic and ferulic acids. 


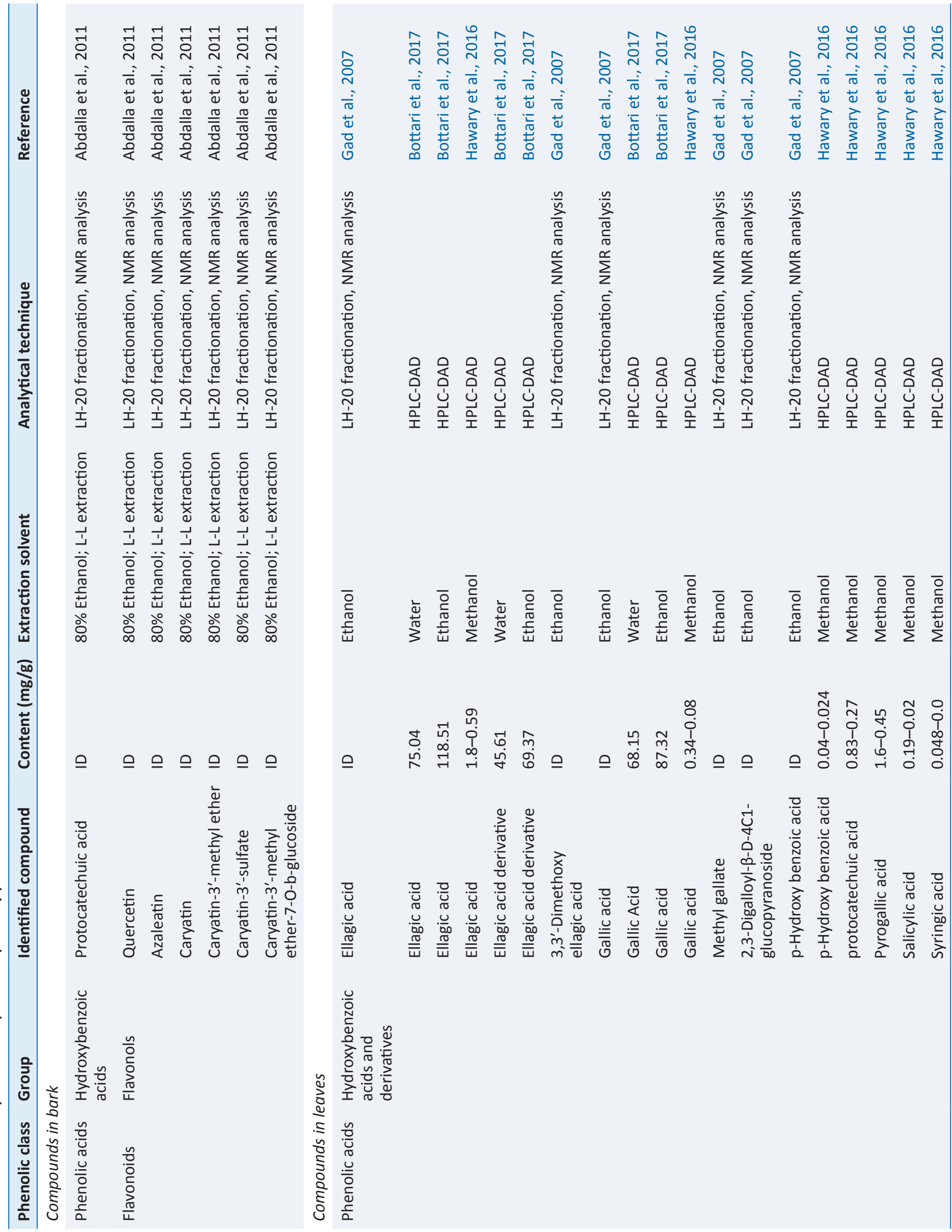




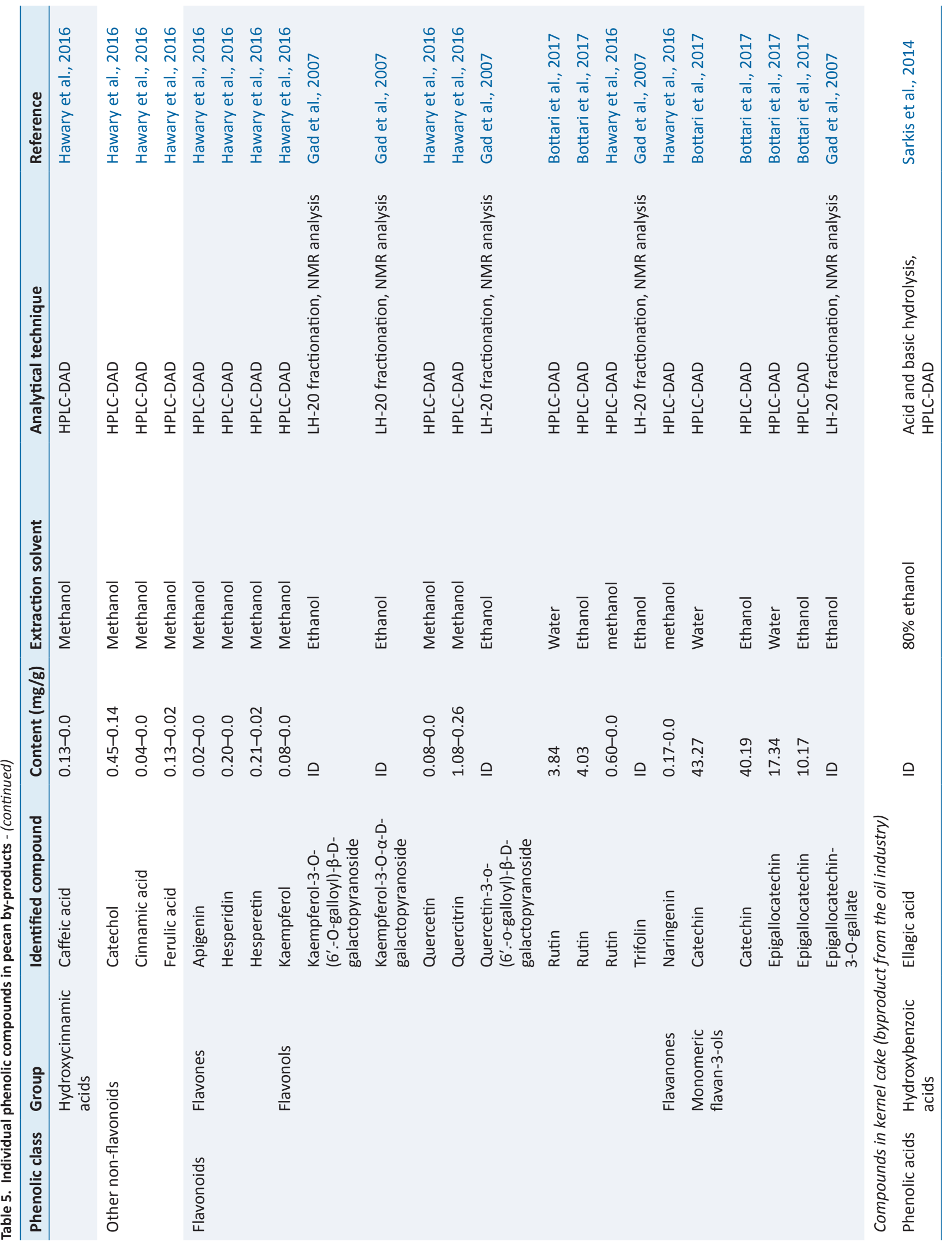




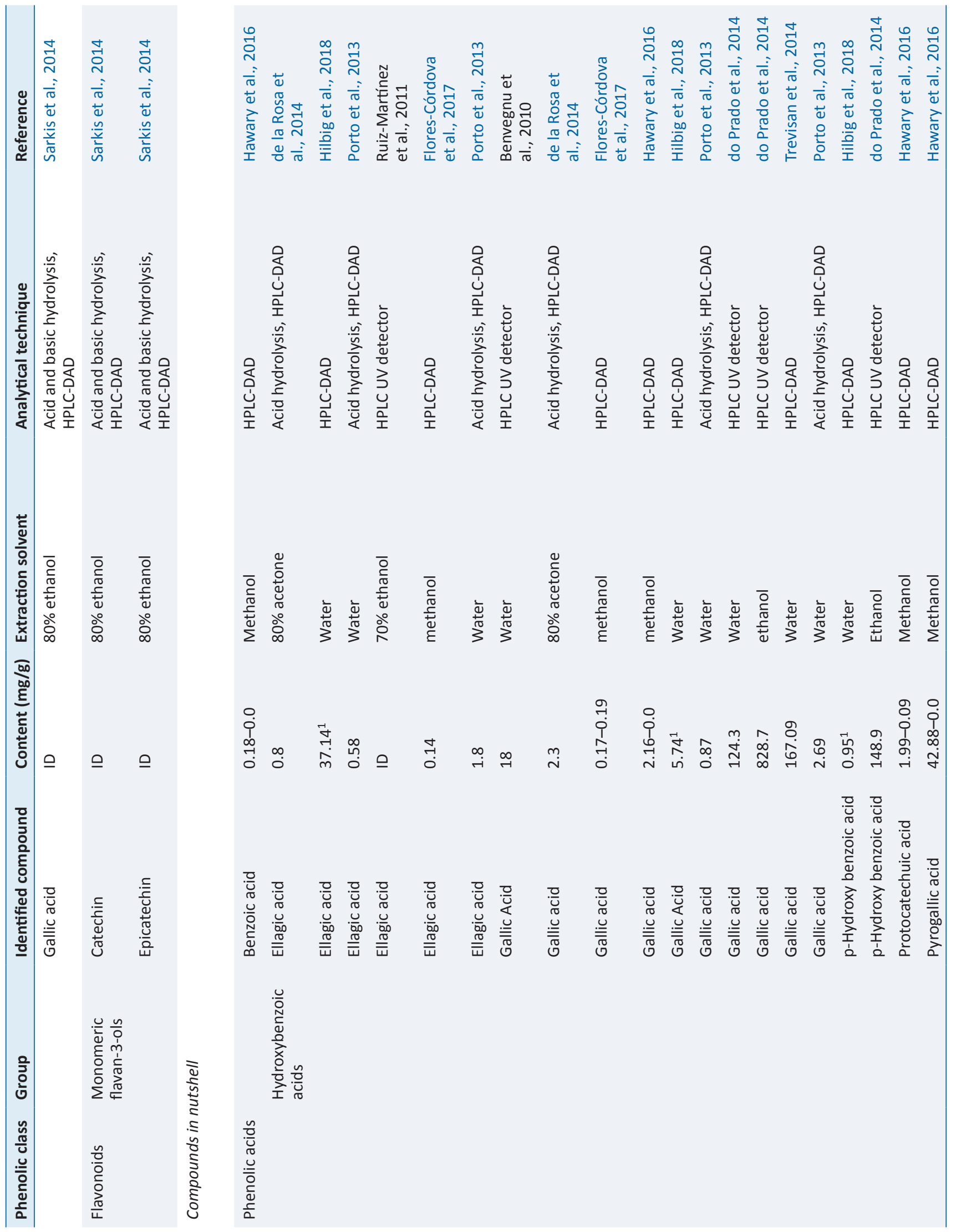




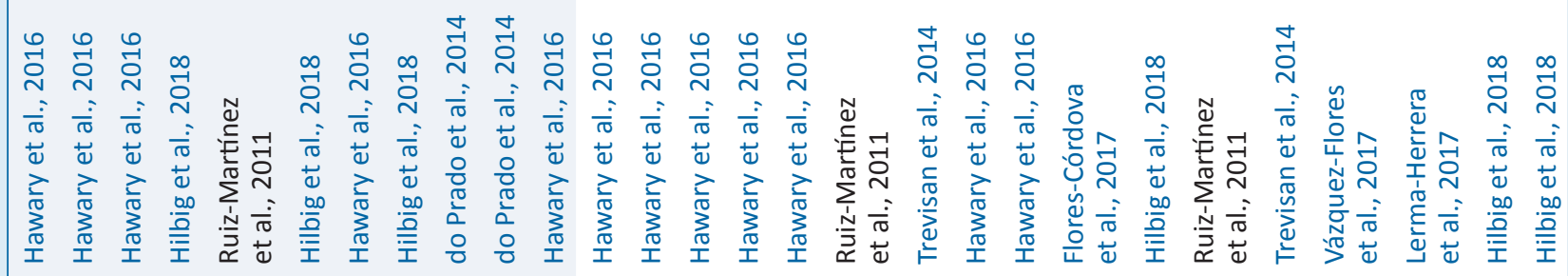

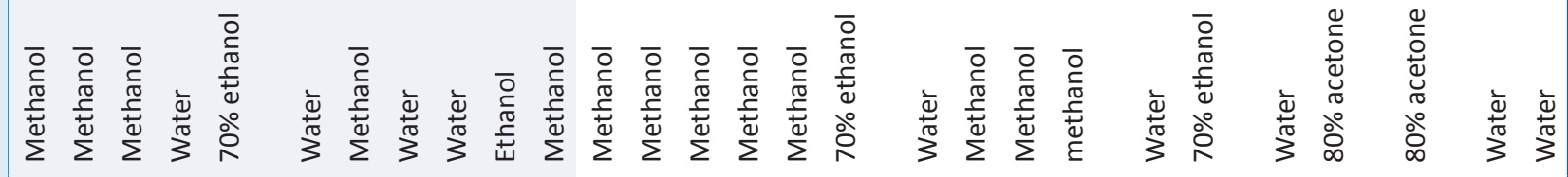

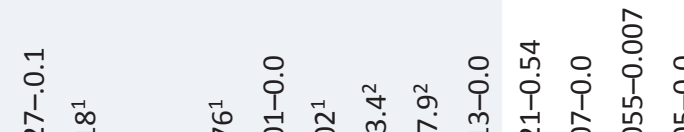

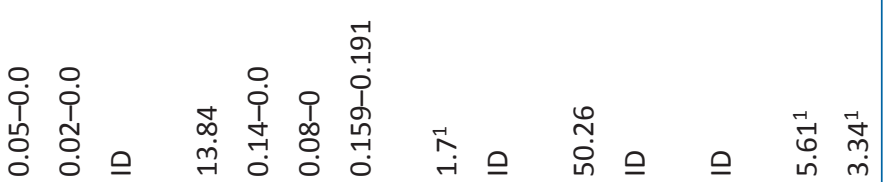

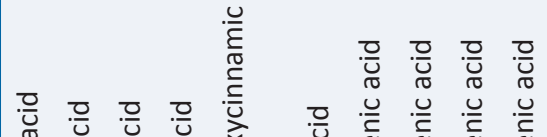

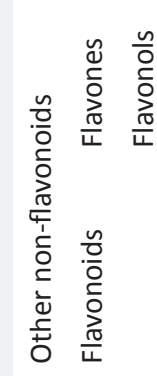




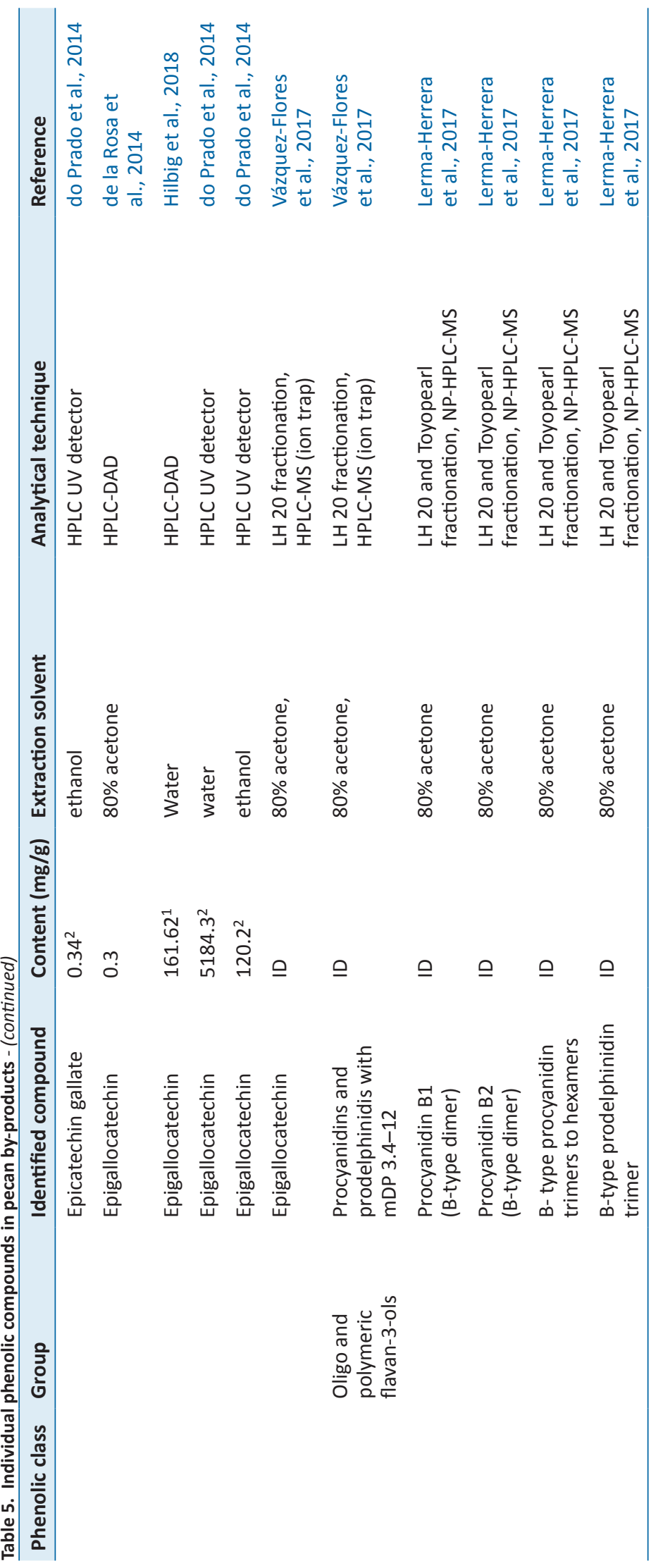

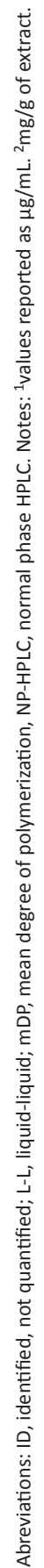


Among flavonoids, monomeric flavan-3-ols catechin, epicatechin, epigallocatechin and epicatechingallate are the most abundant compounds. Flavonols, mainly quercetin and its derivatives (rutin and quercitrin), are the second largest group of flavonoids found in nutshell, and small amounts of flavones (hesperetin) and flavanones (naringenin) have also been reported.

Even though total condensed tannins or proanthocyanidins have only been reported in pecan cake and nutshell, it would be expected that they are present in high amount in pecan leaves and bark. Proanthocyanidins are polymeric and oligmeric flavan-3-ols; their characterization is complex because it involves the determination of their molecular weight, expressed as mean degree of polymerization, the identification of their monomeric units (catechin, epicatechin and their gallates in procyanidins, or gallocatechin, epigallocatechin and their gallates in prodelphinidins) and of the number of bonds between them (two bonds in type-A proanthocyanidins, one bond in type-B). Therefore, only a few recent works have been published on the characterization of these compounds in pecan nutshells. Vázquez-Flores et al. (2017) determined the presence of three different proanthocyanidin fractions with mean degree of polymerization (mDP) of $12,7.3$ and 3.4 in nutshell, after an extraction with $80 \%$ acetone, followed by an isolation through preparative Sephadex LH-20 column. $\mathrm{mDP}$ and procyanidin/prodelphinidin content was determined after a phloroglucinolysis reaction which breaks down the polymer releasing the terminal units as free flavan-3-ols, while forming phloroglucinol-adducts with the non-terminal flavan-3-ols units of the polymer. Nutshell proanthocyanidins showed higher mDPand prodelphinidin content than those obtained from pecan kernel. Lerma-Herrera et al. (2017) isolated two proanthocyanidin fractions from $80 \%$ acetone nutshell extract, and determined its $\mathrm{mDP}$ by normal-phase HPLCMS. Fraction 1 showed amDP of 4.1, while fraction 2 showed a smaller mDP of 3.1. Normal-phase chromatography coupled to MS allowed the identification of dimeric, trimeric, tetrameric, and pentameric B-type procyanidins, as well as trimeric and hexamericprodelphinidins.

\section{Biological activity of pecan nut}

Even though there is a large amount of published information regarding the health benefits of nut consumption (Carey et al., 2012; Chang et al., 2016; Griel and Kris-Etherton, 2006; Kris-Etherton et al., 2001; Mukuddem-Petersen et al., 2005), the number of studies evaluating the specific beneficial effects of pecan nut are scarce, and are summarized in Table 6 . These results can be classified as in vitro, animal studies and human trials.

\subsection{In vitro studies}

Pecan kernel extracts have demonstrated antiproliferative, cell protective, anti-inflammatory, and enzyme-inhibitory activities. The antiproliferative activity of the free polyphenols extracted from ten different nuts (acetone extract with hexane washing) was tested against human liver $\left(\mathrm{HepG}_{2}\right)$ and colon $(\mathrm{Caco}-2)$ cancer cells (Yang et al., 2009). Pecan and walnut showed the highest antiproliferative activity toward both cancer cells andall tested nuts shower lower EC50 values (higher activity) against Caco-2 cells. Weak correlations between soluble free polyphenols and flavonoids and antiproliferative activity were observed, suggesting additive or synergistic interaction of phenolic compounds with other compounds found in the extracts. The biological activity of pecan crude extract and its HMW fraction were also evaluated in vitro by de la Rosa et al. (2014). The antiproliferative activity of the HMW fraction, which showed the highest in vitro antioxidant activity, was tested against a bladder carcinoma cell line (HTB4) and a non-carcinogenic kidney epithelial cell line (LLC-PK1); results indicated that HMW fraction showed higher activity (lower EC50 value) toward the cancer cell than to the non-carcinogenic cell. Interestingly, the EC50 value was 10-30 times lower than those reported in the previous study(Yang et al., 2009) for HepG2 and Caco-2 cell lines, indicating that the HMW fraction may be more active than the crude extract. Additionally, cerebellar granule neurons cells (CGNs) were used to evaluate the protective effect of pecan kernel and shells extracts against $\mathrm{H}_{2} \mathrm{O}_{2}$-induced oxidative damage. When $\mathrm{CNG}$ were pre-incubated with crude kernel extract prior to $\mathrm{H}_{2} \mathrm{O}_{2}$-treatment, a dose-dependent reduction on cytotoxicity was observed, while the pecan nutshell extract (data showed in Table 7) showed 2.5 times higher cytotoxicity compared to kernel, and no protective effect against $\mathrm{H}_{2} \mathrm{O}_{2}$-induced oxidative damage, probably due to the high content of proanthocyanins, and differences in the degree of polymerization of the condensed tannins (de la Rosa et al., 2014).

A crude extract and its low- and high-molecular weight fractions (LMW and HMW, respectively) were evaluated as anti-inflammatory on LPS-stimulated murine RAW 264.7 macrophages, under three different conditions: a) co-incubation of LPS and pecan extracts, b) pre-incubation of the cells with LPS, and c) preincubation of the cells with pecan extracts (Robbins et al., 2016). Results showed that LMW fraction exhibited a dose dependent reduction of NO and ROS production when cells were co-incubated with LPS and extract or when pre-incubated with LPS prior to extract, however, no anti-inflammatory effect was observed with the crude extract or the HMW fraction, indicating that phenolic acids and small tannins found in the LMW fraction exerted this antiinflammatory activity, probably by quenching ROS involved in the

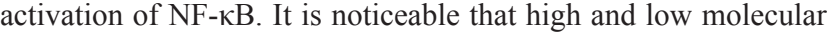
weight compounds may exert different biological effects, this may depend both on the structural characteristics of the compounds and on the biological model that is under study.

Inhibition of digestive enzymes in the small intestine by phenolic compounds has been proposed as one mechanism by which nuts and other proanthocyanidin-rich foods may prevent obesity (Martinez-Gonzalez et al., 2017). The effect of a proanthocyanidin-rich pecan extract fraction (mDP between 1.3 and 4.3) on the inhibition of lipase, amylase and trypsin was studied in a simulated human digestive system. Results showed that this fraction was able to inhibit all three enzymes, probably due to weak non-covalent interactions; these results suggest that even though pecan may reduce lipid and carbohydrate absorption, it can also reduce protein absorption (Vázquez-Flores et al., 2017).

\subsection{Animal studies}

Animal studies have been used to test the protective effect of a pecan-containing diet on cancer and other health conditions related to oxidative stress. Chemicaly induced aberrant crypt foci (AFC) are commonly used as a model to test the effect of diet against cancer development. (Miller et al., 2010) studied the effect of 5 and $10 \%$ whole pecan substituted in isocaloric diets, on the development of azoxymethane-induced AFC in 344 male rats. Results showed a $46-48 \%$ reduction on proximal and distal colon AFC, as well as a reduction on the number of crypt multiplicity, indicating that consumption of pecan was effective in reducing precancerous lesions. Pecan diet increased by approximately two-fold the activ- 


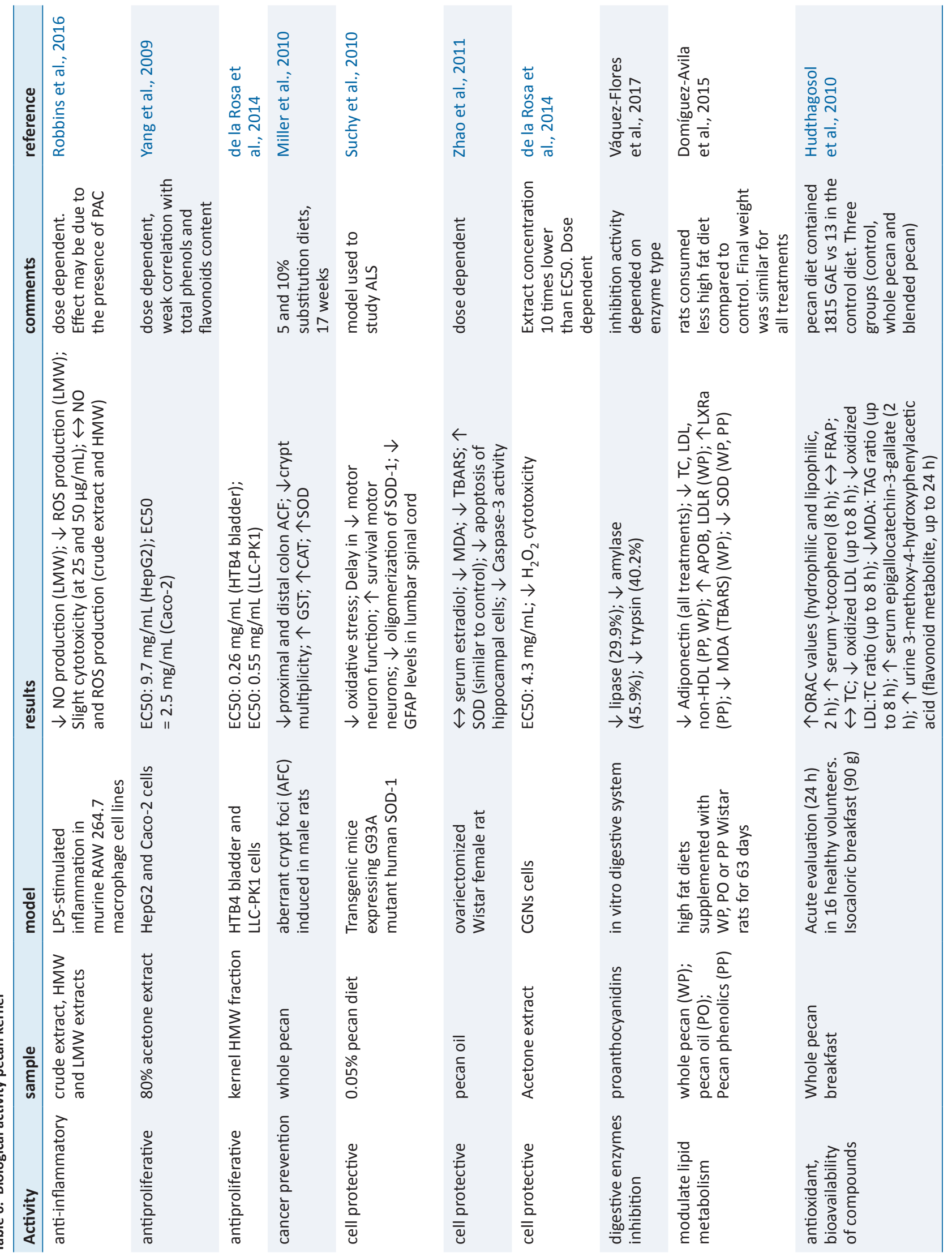




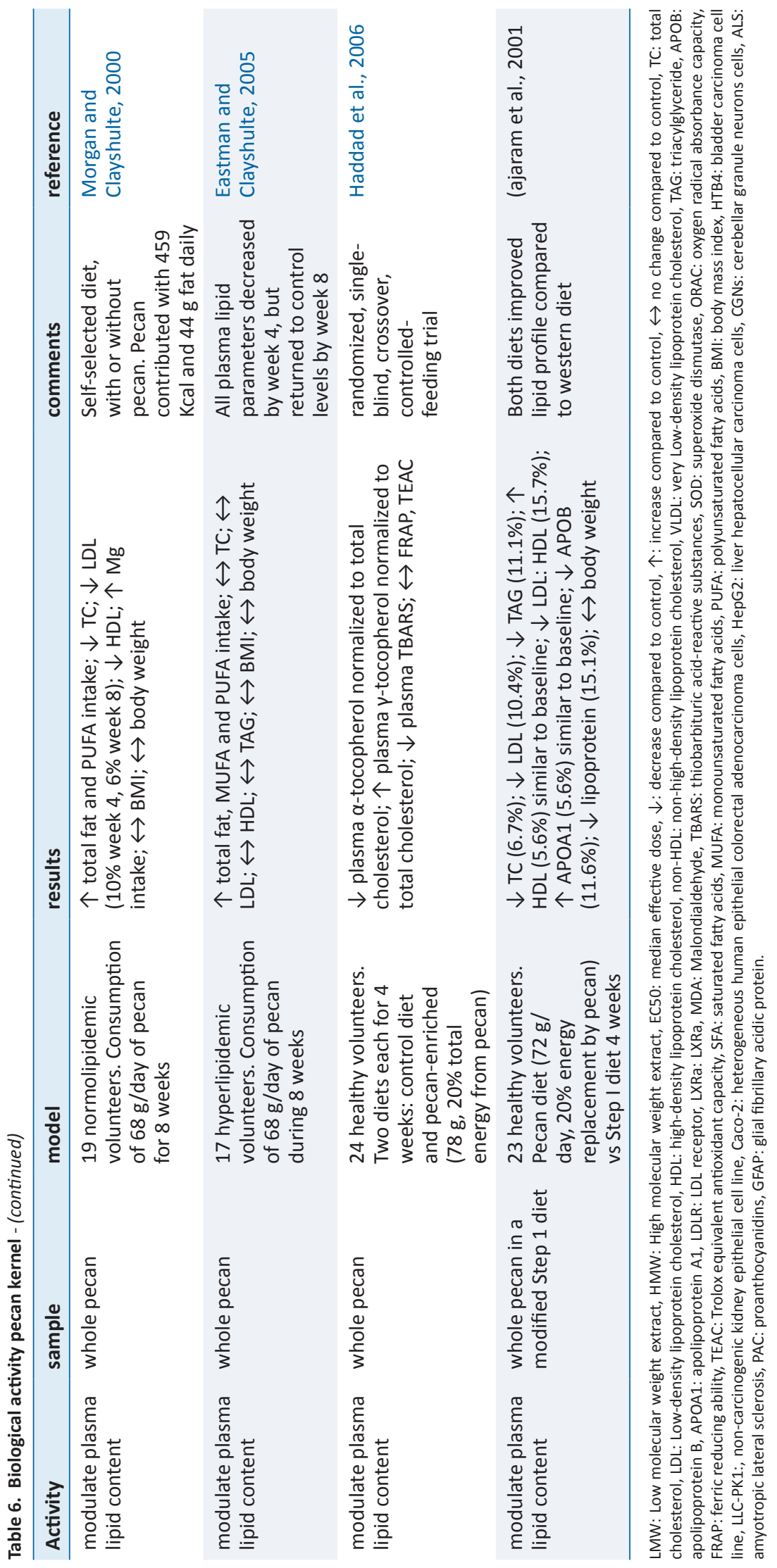




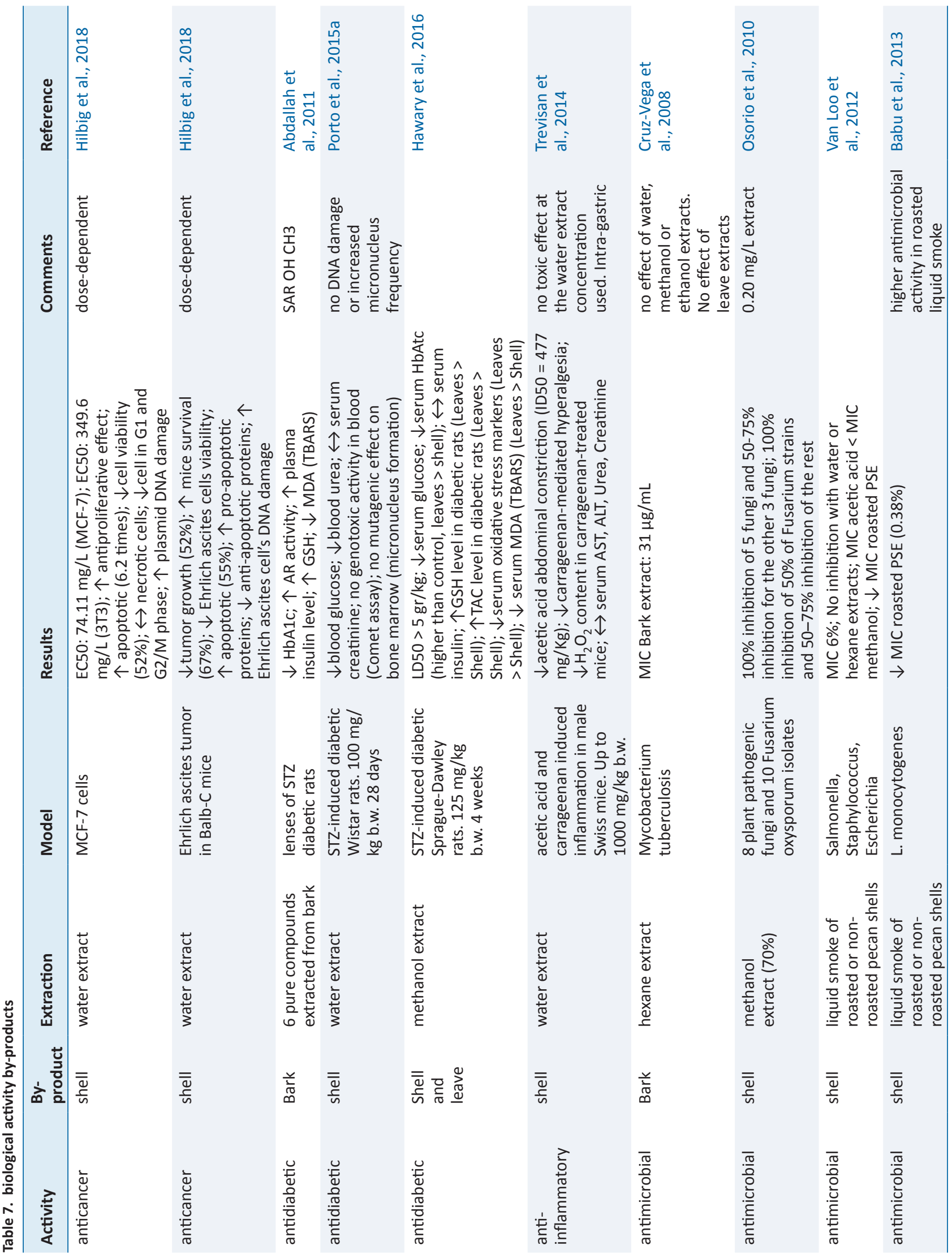




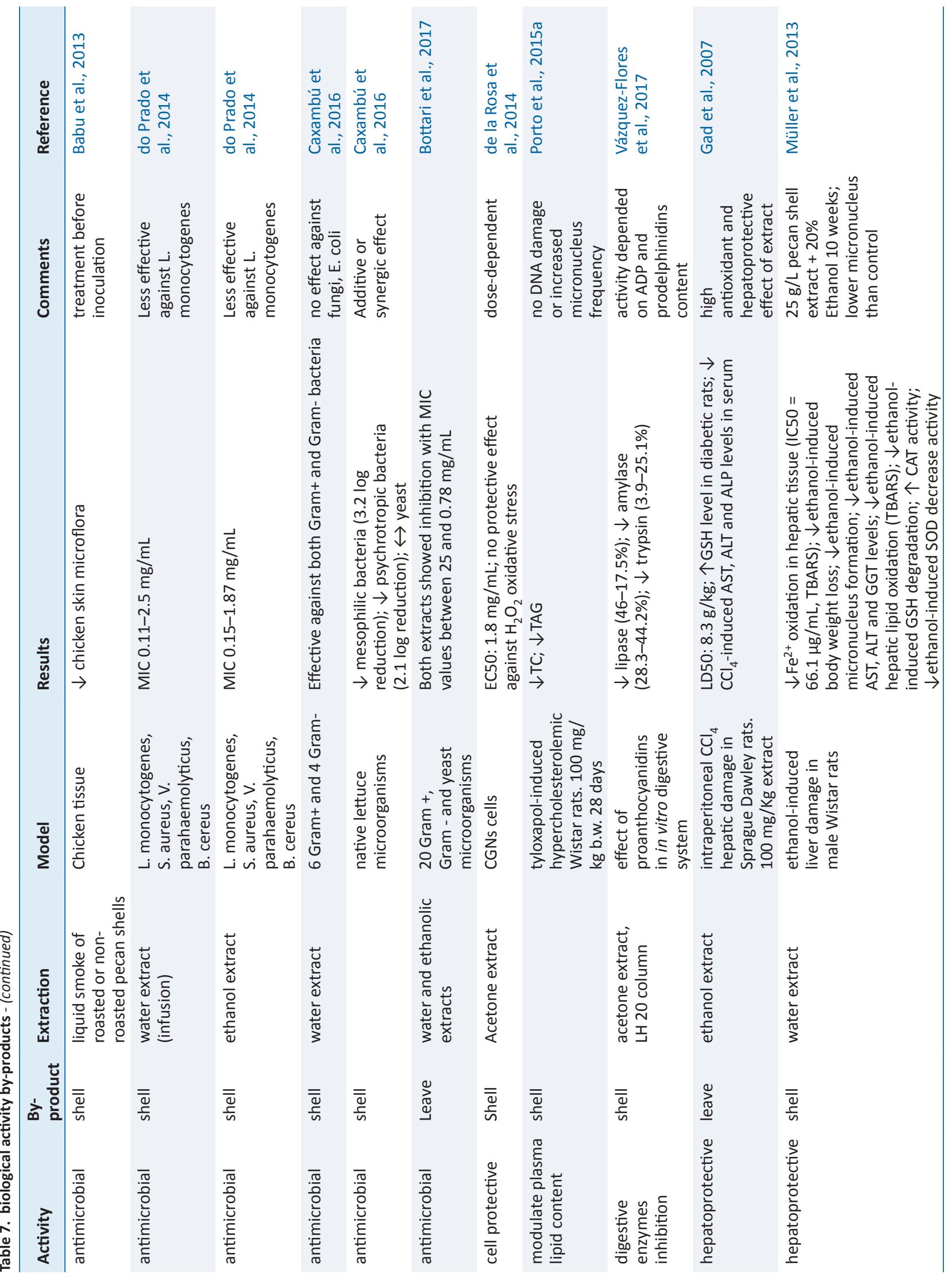




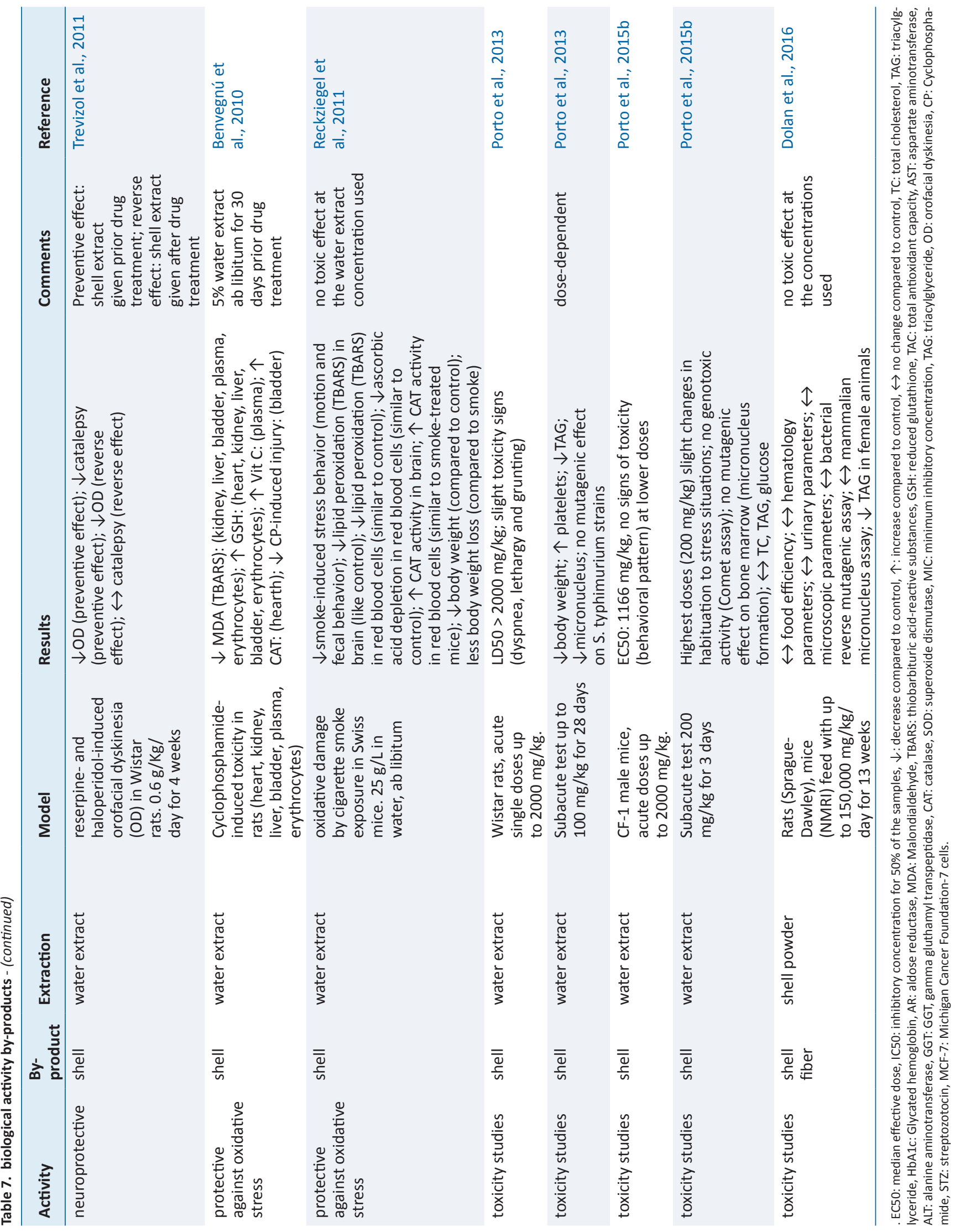


ity of phase II antioxidant enzymes compared to control, which supports the idea that pecan can reduce radical-mediated damage induced by ROS generation by activating the intrinsic antioxidant response.

In another study, Suchy et al. (2010) studied the effect of a $0.05 \%$ pecan diet on the progression of amyotrophic lateral sclerosis (ALS, which is related to motor neuron degeneration, partially due to oxidative stress caused by aberrant function of SOD-1), using transgenic mice expressing G93A mutation of human SOD1 as a model(Suchy et al., 2010). Results showed a reduction on oxidative stress that produced a delay in the signs of motor performance loss, mainly maintaining motor neuron function, reducing SOD-1 aggregation and glial fibrillary acidic protein (GFAP), authors attributed this beneficial effect of pecan to the combination of antioxidant compounds with polyunsaturated fats and vitamin E.

Zhao et al. (2011) evaluated the protective effect of pecan oil against oxidative stress, related to low levels of estrogen, in ovariectomizedWistar female rats. Results showed that pecan oil dosedependently inhibited apoptosis of hippocampal cells through an indirect antioxidant mechanism manifested as an increase in SOD activity and a decrease in malonaldehyde and TBARS content in hippocampus, as well as an inhibition of Caspase- 3 expression.

Domínguez-Avila et al. (2015) evaluated the effect of pecan, its oil and its polyphenol fraction on the lipid profile and liver antioxidant status of Wistar male rats fed with a high-fat diet. At the end of the experiment ( 9 weeks), the weight was similar for all treatments, while the total body fat was higher in all the high fat diets, except for that containing whole pecan (which presented similar body fat to control). The whole pecan diet also reduced total cholesterol, LDL-cholesterol and non-HDL cholesterol compared to the high-fat diet; it also upregulated the expression of apolipoprotein B and LDL-receptor in the liver, and increased the activity of antioxidant enzymes catalase, glutathione-S-transferase and glutathione peroxidase, and decreased the oxidative stress in the liver. Results suggested that the larger beneficial effect of whole pecan may be explained by a synergistic effect between pecan oil and pecan polyphenols.

\subsection{Human studies}

All published human trial studies have evaluated the effect of the consumption of pecan on the plasma lipid content and antioxidant capacity. In a controlled randomized study, 19 normolipidemic volunteers consumed $68 \mathrm{~g}$ of pecan per day in a self-selected diet during eight weeks. The pecan-containing diet resulted in an increase in energy and PUFA intake (9-12\%), however, no differences in body weight or BMI were observed. Total cholesterol, LDLcholesterol and HDL-cholesterol decreased during the experiment, compared to control (Morgan and Clayshulte, 2000). A similar study was carried out by Eastman and Clayshulte(2005), this time with 17 hyperlipidemic participants (total cholesterol $>200 \mathrm{mg}$ / $\mathrm{dL}$, LDL-cholesterol $>130 \mathrm{mg} / \mathrm{dL}$ ). Contrary to the study carried out with normolipidemic participants, in this case no significant changes were observed for plasma lipid parameters at the end of the experiment, even though all parameters decreased by week 4 . The largest decrease in total cholesterol was observed among those participants with the highest initial values. One interesting aspect of these two studies is that they were performed with self-selected diets, so even if the outcomes were modest, they may represent a realistic approach of the beneficial effect of pecan consumption on plasma lipids.

Step I is a diet proposed by the National Cholesterol Education Program (USA) to lower cholesterol, characterized by a high carbohydrate and low fat content, which even though it lowers total cholesterol, also decreases HDL cholesterol and increases triacylglycerides (TAG). Considering these adverse effects of Step I diet, Rajaram et al. (2001) conducted a controlled, single-blind, randomized, crossover feeding study with 23 healthy volunteers to consume Step I or pecan-enriched Step I diet (which included $72 \mathrm{~g}$ of pecan replacing $20 \%$ of the caloric intake in Step I diet) for four weeks. Pecan-enriched diet increased almost by $100 \%$ the MUFA and PUFA intake. Both diets improved lipid profile of participants compared to traditional American diet, however, pecan-enriched diet reduced total cholesterol, LDL-cholesterol, TAG, LDL/HDL ratio, and lipoprotein and increased HDL and APOA1, compared to Step I diet, without modifying body weight. Authors attributed these beneficial effects of pecan consumption to the additive or synergic effect between unsaturated lipids and other non-fat components such as fiber, amino acids and other phytochemicals. In a subsequent study, the same research group conducted a controlled, single-blind, randomized, crossover feeding study with 24 healthy volunteers to compare a control diet with a pecan-enriched diet ( $20 \%$ of total energy provided by pecans) on the plasma tocopherol content and antioxidant capacity (Haddad et al., 2006). Pecan increased plasma $\gamma$-tocopherol normalized to total cholesterol, and decreased plasma $\alpha$-tocopherol normalized to total cholesterol and plasma TBARS, while maintaining plasma antioxidant capacity unchanged, indicating that pecan $\gamma$-tocopherol and polyphenols inhibited in vivo lipid peroxidation and degradation.

In a placebo-controlled, 3-way crossover, acute consumption study;Hudthagosol et al. (2010) evaluated the antioxidant capacity of plasma and polyphenol metabolism over a $24 \mathrm{~h}$ period after the consumption of $90 \mathrm{~g}$ of pecans on 16 healthy volunteers. ORAC values showed a modest increase (10-12\%) $2 \mathrm{~h}$ after consumption, while no changes were observed on FRAP. Plasma $\gamma$-tocopherol and epigallocatechin-3-gallate increased 8 and $2 \mathrm{~h}$ after pecan consumption, respectively. Oxidized LDL and oxidized LDL:TAG ratio decreased up to $8 \mathrm{~h}$ after consumption. Urine 3-methoxy4-hydroxyphenylacetic acid (flavonoid metabolite) increased during the $24 \mathrm{~h}$ period. These results suggested that pecan phenolic compounds were absorbed and metabolized, and that the plasma antioxidant capacity may be due to the additive or synergic effect of both tocopherols and phenolic compounds. Beneficial health effects of pecan consumption are summarized in a systematic review and meta-analysis study published by Blanco Mejia et al. (2013).

\section{Biological activity of pecan by-products}

Ethnobotanical uses of pecan by-products include the consumption of infusions made from the leaves or nutshells for the treatment and prevention of diabetes, obesity, hypertension, hypercholesterolemia, cancer, tuberculosis, and other oxidative stress-related diseases (Caxambú et al., 2016; Gad et al., 2007; Hilbig et al., 2018; Trevisan et al., 2014). Several studies have been carried out using pecan by-products, mainly as antimicrobial, antidiabetic and cell protective (Table 7).

Considering that pecan by-products are not foods, it is necessary to determine their acute and subacute toxicity, to guaranty the safety for its consumption, according to the Economic Cooperation andDevelopment (OECD) guidelines. Toxicological studies have been performed for nutshells and leaves. Gad et al. (2007)determined an LD50 of $8.3 \mathrm{~g} / \mathrm{kg}$ for an ethanolic leave extract in Sprague Dawley rats. Porto et al. (2015b) determined the acute LD50 of aqueous nutshell extracts to be higher than $2 \mathrm{~g} /$ $\mathrm{kg}$ for Wistar rats and $1166 \mathrm{mg} / \mathrm{kg}$ for CF-1 mice. Hawary et al. 
(2016) determined that the acute LD50 was higher than $5 \mathrm{~g} / \mathrm{kg}$ for both nutshell and leave methanolic extracts. In subacute studies, Porto et al. (2013) determined that no toxic effect was observed on Wistar rats summited to doses of $100 \mathrm{mg} / \mathrm{kg}$ for 28 days, a doses that showed some beneficial effects, such as decrease in TAG and body weight. The same group (Porto et al., 2015b) observed no toxic effect of doses up to $200 \mathrm{mg} / \mathrm{kg}$ for 3 days in CF-1 mice. Authors concluded that when using nutshell extracts the high levels of inorganic elements should be considered for safety reasons. No toxic effectwas observed by Dolan et al. (2016) who administered up to $150,000 \mathrm{mg} / \mathrm{kg} /$ day of nutshell powder mix in the diet to rats and mice for 13 weeks, observing a decrease in TAG, probably due to the high content of fiber and phenolic compounds.

Several pecan by-products show antimicrobial activity. Hexane extracts from the pecan tree bark showed antimicrobial activity against Mycobacterium tuberculosis, with a MIC of $31 \mu \mathrm{g} / \mathrm{mL}$ (Cruz-Vega et al., 2008), while water and ethanolic extracts from leaves showed antimicrobial activity against $20 \mathrm{Gram}+$, Gramand yeast microorganisms wit MIC values between 25 and 0.78 $\mathrm{mg} / \mathrm{mL}$ (Bottari et al., 2017); in general terms, ethanolic extracts showedd better activity. Authors proposed that this antimicrobial activity might be due to the presence of phenolic acids, flavonoids and tannins in the extracts.

Two studies demonstrated that liquid smoke (LS), a product obtained from roasted or non-roasted pecan nutshell that is normally used as a flavoring agent, presented antimicrobial activity against foodborne pathogens (Escherichia, Salmonella and Staphylococcus). LS obtained with roasted pecan nutshell showed higher inhibition compared to non-roasted nutshells, probably due to the formation of Maillard compounds during roasting process (Van Loo et al., 2012). These authors also observed that LS extracts obtained with acetic acid showed higher inhibition than those obtained with methanol, while no inhibition was observed when water or hexane were used as extraction solvents. Babu et al. (2013) obtained nutshell LS extract using a vacuum extraction process. Roasted LS showed lower MIC against Listeria monocytogenes than nonroasted LS. Roasted LS extract reduced 2-log normal chicken skin microflora, and when applied before inoculation with Listeria, a 4-log reduction was obtained, showing that pecan nutshell LS extract could be used as a natural antimicrobial for meat processing.

do Prado et al. (2014) evaluated water and ethanol nutshell extracts against Gram + bacteria, observing that water extracts showed higher antimicrobial activity. The extract showed a higher inhibition than pure phenolic compounds, indicating either synergic effects or the presence of unidentified compounds that could be responsible for this effect. A methanolic nutshell extract showed a remarkable effectiveness against eight plant pathogenic fungi strains (Osorio et al., 2010). Authors attributed this high antifungal activity to the high concentration of hydrolysable and condensed tannins. Caxambú et al. (2016) evaluated the effectiveness of a water pecan nutshell extract against Gram+ and Gram- bacteria, and food pathogens. No inhibition was observed for E. coli or fungi. The extract showed higher antimicrobial activity than pure phenolic compounds, suggesting that the activity of the extract was due to the combination of different mechanisms, among them: oxidation of cell membranes, metal chelation and extracellular enzyme inhibition. When the nutshell extract was used against native microorganisms in lettuce, mesophilic and psychrotropic bacteria were inhibited, while no inhibition on yeast was observed.

Other biological actions that pecan by-products have demonstrated include anticancer, antidiabetic, antinflammatory, enzyme inhibition and protection against oxidative stress in liver brain and other tissues. Hilbig et al. (2018) studied the anticancer activity of aqueous nutshell extracts on a breast cancer cell line (MCF-
7) and in Ehrlich ascites carcinoma in Balb-C mice. The extract showed 4.7 times higher cytotoxicity against MCF-7 cells against than non-cancerous cells (3T3 cells); it showed antiproliferative and apoptotic effects as well as cell cycle arrest, decreasing cell viability in a dose-dependent way, while no effect was observed inthe number of necrotic cells. Authors also showed that the nutshell extract increased the expression of proteins involved in apoptotic cell death and decreased in the expression of anti-apoptotic proteins and those associated with the cycle arrest. In the in vivo study, a decrease in tumor growth (52\%) and Ehrlich ascites cells viability was observed, which was reflected in an increase of apoptotic of tumor cells, and mice survival (67\%).

Several works have focused on the antidiabetic activity of pecan by-products. Abdallah et al. (2011) evaluated the antidiabetic activity of seven pure compounds (six flavonoids and protocatechuic acid) isolated from pecan bark on streptozotocin-induced diabetic rats. Quercetin, caryatin-3'methyl ether and caryatin-3'methyl ether-7-O- $\beta$-D-glucoside showed the most potent antidiabetic effect, expressed as an increase in aldose reductase inhibition and plasma insulin level, accompanied with an increase on the antioxidant status (increase in glutathione and a decrease in lipid peroxidation) and glycated hemoglobin. Authors found a marked structure-activity relationship between substituents in the flavonoid ring and their activity, observing that methylation at positions 3,5 and $3^{\prime}$ were responsible for the increased aldose reductase inhibition. In a study conducted byPorto et al. (2015a),streptozotocin-induced diabetic Wistar rats were supplemented with $100 \mathrm{mg} / \mathrm{kg}$ water nutshell extract for 28 days. No genotoxic activity in blood cells (Comet assay) or mutagenic effect on bone marrow (micronucleus formation) was observed, indicating that it's safe to use the extract at the selected doses. At the end of the experiment, a decrease in blood glucose and urea levels were observed. The extract given at the same dose was also effective to decrease total cholesterol and tryacilglicerides in tyloxapol-induced hypercholesterolemia. Hawary et al. (2016) also used the streptozotocin-induced diabetic rat model to evaluate the antidiabetic activity of nutshell and leave methanolic extracts. Diabetic Sprague-Dawleyrats were treated with $125 \mathrm{mg}$ of extract/ $\mathrm{kg}$ for 4 weeks, observing a decrease in serum glucose, glycated hemoglobin, oxidative stress markers and lipid peroxidation ( $\downarrow$ MDA, measured by TBARS); serum insulin remained unchanged, while glutathione and total antioxidant capacity increased. Interestingly, all parameters were more affected by leaves than by nutshell, due to their higher flavonoid content (good correlation between total flavonoids and evaluated parameters). Authors attributed this antidiabetic effect of both leaves and nutshells to the capacity of phenolic compounds to inhibit digestive enzymes such as $\alpha$-lipase. The inhibition of digestive enzymes by a nutshell proanthocyanidin extract was studied by VazquezFlores et al. (2017), the authors observed that the partially purified proanthocyanidins inhibited digestive enzymes (lipase, amylase and trypsin) in a simulated human digestive system, even though in a lesser degree compared to kernel proanthocyanidins(VázquezFlores et al., 2017). The authors proposed that the inhibition activity of the extracts depended on the degree of polymerization and prodelphinidin content of the condensed tannins, as well as the enzyme structure.

Trevisan et al. (2014) studied the anti-inflammatory activity of a water nutshell extract in acetic acid/carrageenan-induced inflammation in Swiss mice, observing a dose-dependent reduction of abdominal constriction, hyperalgesia, and $\mathrm{H}_{2} \mathrm{O}_{2}$ content, with no toxic effect at concentrations up to $1 \mathrm{~g} / \mathrm{kg}$ (Trevisan et al., 2014). Hepatoprotective effects of leaves (Gad et al., 2007) and nutshell (Müller et al., 2013) extracts have been studied. One hundred mg/ $\mathrm{kg}$ ethanol leave extract reverted the $\mathrm{CCl}_{4}$-induced hepatic dam- 
age in Sprague Dawley rats by increasing glutathione levels and decreasing the levels of enzymes associated with hepatocellular damage; this effect was probably due to the high content of phenolic compounds in the extract (Gad et al., 2007). A water nutshell extract was able to revert ethanol-induced liver damage in Wistar rats by inducing a reduction on hepatic tissue oxidation, levels of enzymes associated with hepatocellular damage, and an increase of antioxidant enzymes activity and plasma antioxidant capacity (Müller et al., 2013). The neuroprotective effect of a nutshell water extract was evaluated against reserpine- and haloperidol-induced orofacial dyskinesia (OD) in Wistar rats, observing that the extract prevented OD and catalepsy induced by both drugs, and was able to revert the OD effect, when rats consumed $0.6 \mathrm{~g} / \mathrm{kg} /$ day for 4 weeks(Trevizol et al., 2011). Authors suggested that the phenolic compounds present in the extract neutralized the oxidative stress generated by both drugs.

The protective effect of nutshell extracts has been studied in other animal models of oxidative stress. A water nutshell extract protected Wistar rats against generalized oxidative stress induced by cyclophosphamide (Benvegnú et al., 2010). Animals were supplemented with a $5 \%$ water extract at libitum for 30 days prior to drug administration. Authors observed a reduction on lipid peroxidation, and an increase in glutathione in different tissues, as well as a decrease in cyclophosphamide-induced injuries. In a related study, ab libitum consumption of a $25 \mathrm{~g} / \mathrm{L}$ water extract showed a protective effect against cigarette smoke-induced oxidative damage in Swiss mice(Reckziegel et al., 2011). Results showed that the nutshell extract reduced the smoke-induced alterations in behavior, lipid peroxidationin brain and in red blood cells, the ascorbic acid depletion in red blood cells, and increased the CAT activity in brain and in red blood cells.

\section{Concluding remarks}

Pecan nuts are nutritious foods rich in healthy fatty acids, fiber, vitamins and minerals. They also contain a wide array of bioactive phytochemicals including phytosterols, lipophilic antioxidants like $\gamma$-tocopherol, and hydrophilic polyphenols. Pecan oil is nowadays commercially available and is attractive for its high content of oleic and linoleic acids, $\gamma$-tocopherol and $\beta$-sitosterol. In addition to these edible products, other parts of the pecan tree are sources of bioactive compounds. Polyphenols are especially concentrated in the hard shell of the pecan nut, which is discarded in the pecan processing facilities and is therefore a potentially useful byproduct. Another important pecan byproduct is the kernel cakes obtained after oil extraction in which many bioactive compounds are left behind. The leaves and bark of the pecan tree also contain bioactive compounds, especially flavonoids. Although the fatty acid composition and most bioactive components of the pecan oil have been described in some detail and have been reported for different pecan cultivars and sampling locations; complete characterization of the pecan polyphenolic compounds is still far from complete. This is in part due to the remarkable content of condensed and hydrolysable tannins, polymeric polyphenols whose identification and quantification is complex. Acetone extraction is the best alternative to obtain high tannin extracts, so most characterization studies have been carried out in this type or extract, mostly in pecan kernels. Hydrolysable tannins can also be extracted in water and ethanol, and these solvents have been used extensively for pecan by-products, but identification of individual hydrolysable tannins is lacking. There are also very few studies that attempt to identify and characterize condensed tannins in pecan by-products, and these few works have been performed only in nutshell acetone extracts.

Whole pecan kernels, pecan oil, kernel extracts and extracts of the different pecan by-products have shown diverse biological actions in diverse models of study. Whole kernels and oil have been used as part of the diet in human and animal trials, showing mostly effects on lowering plasma lipids and improving the antioxidant status; although, in animal studies, it has been possible to observe changes in gene expression due to the consumption of pecan kernels, oil, or a pecan kernel extract. Pecan kernel extracts have also shown various in vitro effects, including antiproliferative, cell-protective, anti-inflammatory via inhibition of ROS production, and inhibition of digestive enzymes. Biological activities of pecan byproducts have been tested in vitro and in animal studies and most works have used an aqueous nutshell extract. The most important bioactivities are antimicrobial, anti-diabetic and protection against different forms of oxidative stress (induced by inflammation, different chemical compounds or cigarette smoke).

It seems clear than pecans provide valuable health benefits, similar to other tree nuts, and that pecan shells, leaves and other by-products can be used as sources of bioactive compounds with possible application as nutraceuticals. However, in order to take full advantage of the potential benefits of pecan nut and its byproducts, more studies are needed in order to complete the complex phytochemical profile of the extracts that show bioactivity and to understand the possible molecular targets and biochemical mechanisms of action of the bioactive compounds. In this regard, since pecan is rich in tannins, extensive metabolism of these compounds is expected to occur in the digestive tract, especially in the colon and this is also a promising area for future research.

\section{Acknowledgments}

We are thankful for the financial support of the Mexican NationalCouncil for Science and Technology, (CONACYT Project CB2016-286449).LAdR and EAP also aknowledge UACJ for granting them sabbatical leaves.

\section{References}

Abdallah, H.M., Salama, M.M., Abd-elrahman, E.H., and El-Maragny, S.A (2011). Antidiabetic activity of phenolic compounds from Pecan bark in streptozotocininduced diabetic rats. Phytochem. Let. 4: 337-341.

Alasalvar, C., and Bolling, B.W. (2015). Review of nut phytochemicals, fatsoluble bioactives, antioxidant components and health effects. Br. J. Nutr. 113: S68-S78.

Alexander, W.S., Brusewitz, G.H., and Maness, N.O. (1997). Pecan oil recovery and composition as affected by temperature, pressure, and supercritical $\mathrm{CO}_{2}$ flow rate. J. Food Sci. 62(4): 762-766.

Babu, D., Crandall, P.G., Johnson, C.L., O’Brian, C.A., and Ricke, S. (2013). Efficacy of Antimicrobials Extracted from Organic Pecan Shell for Inhibiting the Growth of Listeria spp. J. Food Sci. 78(12): M1899M1903.

Benvegnú, D.M., Barcelos, R.C.S., Boufleur, N., Reckziegel, P., Pase, C.S., Müller, L.G., Martins, N.M.B., Vareli, C., and Bürger, M.E. (2010). Protective Effects of a By-Product of the Pecan Nut Industry (Carya illinoensis) on the Toxicity Induced by Cyclophosphamide in Rats Carya illinoensis Protects Against Cyclophosphamide-Induced Toxicity. J. Environ. Pathol. Toxicol. Oncol. 29(3): 185-197.

Bhagwat, S., and Haytowitz, D.B. (2015). USDA Database for the Flavonoid Content of Selected Foods Release 3.2. https://www.ars.usda.gov/ARSUserFiles/80400525/Data/Flav/Flav3.2.pdf. Accesed 24 Nov. 2017.

Bittner, K., Rzeppa, S., and Humpf, H.-U. (2013). Distribution and quantification of flavan-3-ols and procyanidin with low degree of polym- 
erization in nuts, cereals, and legumes. J. Agric. Food Chem. 61: 9148-9154.

Blanco Mejia, S., Kendall, C.W.C., Viguiliouk, E., Augustin, L.S., Ha, V., Cozma, A.I., Mirrahimi, A., Maroleanu, A., Chiavaroli, L., Leiter, L.A., de Souza, R.J., Jenkins, D.J.A., and Sievenpiper, J.L. (2013). Effect of tree nuts on metabolic syndrome criteria: a systematic review and metaanalysis of randomised controlled trials. BMJ Open 4: e004660.

Blomhoff, R., Carlsen, M.H., Andersen, L.F., and Jacobs Jr, D.R. (2006). Health benefits of nuts: potential role of antioxidants. Br. J. Nutr. 96(2): S52-S60.

Bolling, B.W., Chen, C.-Y.O., McKay, D.L., and Blumberg, J.B. (2011). Tree nut phytochemicals: composition, antioxidant capacity, bioactivity, impact factors. A systematic review of almonds, Brazils, cashews, hazelnuts, macadamias, pecans, pine nuts, pistachios and walnuts. Nut. Res. Rev. 24: 244-275.

Bottari, N.B., Soare Lopes, L.Q., Pizzuti, K., dos Santos Alves, C.F., Saldanha Corréa, M., Perger Bolzan, L., Zago, A., de Almeida Vaucher, R., Boligon, A.A., Giongo, J.L., Baldissera, M.D., and Santos, R.C.V. (2017). Antimicrobial activity and phytochemical characterization of Carya illinoensis. Micro. Pathog. 104: 190-195.

Bouali, I., Trabelsi, H., Abdallah, I.B., Albouchi, A., Martine, L., Grégoire, S., Bouzaien, G., Gandour, M., Boukhchina, S., and Berdeaux, O. (2013). Changes in fatty acid, tocopherol and xanthophyll contents during the development of Tunisian-grown pecan nuts. J. Am. Oil Chem. Soc. 90: 1869-1876

Bouali, I., Trabelsi, H., Herchi, W., Martine, L., Albouchi, A., Bouzaien, G., Sifi, S., Boukhchina, S., and Berdeaux, O. (2014). Analysis of pecan nut (Carya illinoinensis) unsaponifiable fraction. Effect of ripening stage on phytosterols and phytostanols composition. Food Chem. 164: 309-316.

Burns, R.M., and Honkala, B.H. (1990). Silvics of North America. Volume 2. Hardwoods. United States Department of Agriculture (USDA), Forest Service. https://www.srs.fs.usda.gov/pubs/1548.

Carey, A.N., Poulose, S.M., and Shukitt-Hale, B. (2012). The beneficial effects of tree nuts on the aging brain. Nutr. Aging. 1: 55-67.

Castelo-Branco, V.N., Santana, I., Di-Sarli, V.O., Freitas, S.P., and Torres, A.G. (2016). Antioxidant capacity is a surrogate measure of the quality and stability of vegetable oils. Eur. J. Lipid Sci. Tech. 118: 224-235.

Caxambú, S., Biomdo, E., Kolchinski, E.M., Padilha, R.L., Brandelli, A., and Sant'Anna, V. (2016). Evaluation of the antimicrobial activity of pecan nut [Carya illinoinensis (Wangenh) C. Koch] shell aqueous extract on minimally processed lettuce leaves. Food Sci. Technol. 36(Supp. 1): $42-45$.

Chang, S.K., Alasalvar, C., Bolling, B.W., and Shahidi, F. (2016). Nuts and their co-products: The impact of processing (roasting) on phenolics, bioavailability, and health benefits-A comprehensive review. J. Funct. Foods 26: 88-122.

Chun, J., Lee, J., Ye, L., and Eitenmiller, R.R. (2002). Effects of variety and crop year on tocopherols in pecans. J. Food Sci. 67(4): 1356-1359.

Cruz-Vega, D.E., Verde-Star, M.J., Salinas-González, N., Rosales-Hernández, B., Estrada-García, I., Mendez-Aragón, P., Carranza-Rosales, P., González-Garza, M.T., and Castro-Garza, J. (2008). Antimycobacterial Activity of Juglans regia, Juglans mollis, Carya illinoensis and Bocconia frutescens. Phytother. Res. 22: 557-559.

de la Rosa, L.A., Alvarez-Parrilla, E., and Shahidi, F. (2011). Phenolic Compounds and Antioxidant Activity of Kernels and Shells of Mexican Pecan (Carya illinoinensis). J. Agric. Food Chem. 59(1): 152-162.

de la Rosa, L.A., Vázquez-Flores, A.A., Alvarez-Parrilla, E., Rodrigo-García, J., Medina-Campos, O.N., Ávila-Nava, A., González-Reyes, S., and Pedraza-Chaverri, J. (2014). Content of major classes of polyphenolic compounds, antioxidant, antiproliferative, and cell protective activity of pecan crude extracts and their fractions. J. Funct. Foods. 7: 219-228.

Derewiaka, D., Szwed, E., and Wolosiak, R. (2014). Physicochemical properties and composition of lipid fraction of selected edible nuts. Pak. J. Bot. 46(1): 337-343.

do Prado, A.C.P., da Silva, H.S., da Silveira, S.M., Barreto, P.L.M., Vieira, C.R.W., Maraschin, M., Ferreira, S.R.S., and Block, J.M. (2014). Effect of the extraction process on the phenolic compounds profile and the antioxidant and antimicrobial activity of extracts of pecan nut [Carya illinoinensis (Wangenh) C. Koch] shell. Ind. Crops Prod. 52: 552-561.
Dolan, L., Matulka, R., Worn, J., and Nizio, J. (2016). Safety studies conducted on pecan shell fiber, a food ingredient produced from ground pecan shells. Toxicol. Rep. 3: 87-97.

Domínguez-Avila, J.A., Alvarez-Parrilla, E., González-Aguilar, G.A., VillaRodríguez, J., Olivas-Orozco, G.I., Molina-Corral, J., Gómez-García, M.C., and de la Rosa, L.A. (2013). Influence of growing location on the phytochemical content of pecan (Carya illinoinensis) oil. J. Food Res. 2(5): 143-151.

Domínguez-Avila, J.A., Alvarez-Parrilla, E., López-Díaz, J.A., MaldonadoMendoza, I.E., Gómez-García, M.C., and de la Rosa, L.A. (2015). The pecan nut (Carya illinoinensis) and its oil and polyphenolic fractions differentially modulate lipid metabolism and the antioxidant enzyme activities in rats fed high-fat diets. Food Chem. 168: 529-537.

Eastman, W.A., and Clayshulte, B.J. (2005). Pecan Effects on Serum Lipoproteins and Dietary Intakes of Hyperlipidemic Individuals Consuming Self-Selected Diets. Fam. Consum. Sci. Res. J. 33(3): 197-207.

Economic Research Service. (2017a). Economic Research ServiceFruit and Tree Nut Yearbook Tables. https://www.ers.usda.gov/data-products/fruit-and-tree-nut-data/fruit-and-tree-nut-yearbook-tables/ \#TreeNuts. Accessed 29 Mar. 2018.

Economic Research Service. (2017b). Economic Research Servicelmports and exports of fruit and tree nuts. https://www.ers.usda.gov/dataproducts/fruit-and-tree-nut-data/data-by-commodity/. Accessed 29 Mar. 2018.

Fernandes, G.D., Gómez-Coca, R.B., Pérez-Camino, M.C., Moreda, W., and Barrera-Arellano, D. (2017). Chemical characterization of major and minor compounds of nut oils: almond, hazelnut, and pecan nut. J. Chem. 2017: 2609549.

Flores-Córdova, M.A., Sánchez, E., Muñoz-Márquez, E., Ojeda-Barrios, D.L., Soto-Parra, J.M., and Preciado-Rangel, P. (2017). Phytochemical composition and antioxidant capacity in Mexican pecan nut. Emir. J. Food Agric. 29(5): 346-350.

Gad, H.A., Ayoub, N.A., and Al-Azizi, M.M. (2007). Phenolic constituentswith promising antioxidant and hepatoprotective activities fromthe leaves extract of Carya illinoinensis. Nat. Prod. Ind. J. 3(3): 151-158.

Gong, Y., and Pegg, R.B. (2017). Separation of ellagitannin-rich phenolics from U.S. pecans and Chinese hickory nuts using fused-core HPLC columns and their characterization. J. Agric. Food Chem. 65: 58105820.

Gong, Y., Pegg, R.B., Carr, E.C., Parrish, D.R., Kellett, M.E., and Kerrihard, A.L. (2017). Chemical and nutritive characteristics of tree nut oils available in the U.S. market. Eur. J. Lipid Sci. Tech. 119: 1-15.

Griel, A.E., and Kris-Etherton, P.M. (2006). Tree nuts and the lipid profile: a review of clinical studies. Br. J. Nutr. 96(2): S68-S78.

Gu, L., Kelm, M.A., Hammerstone, J.F., Beecher, G., Holden, J., Haytowitz, D., Gebhardt, S., and Prior, R.L. (2004). Concentrations of proanthocyanidins in common foods and estimations of normal consumption. J. Nut. 134(3): 613-617.

Haddad, E., Jambazian, P., Karunia, M., Tanzma, J., and Sabaté, J. (2006) A pecan-enriched diet increases c-tocopherol/cholesterol and decreases thiobarbituric acid reactive substances in plasma of adults. Nutr. Res. 26: 397-402.

Hawary, S.S., Saad, S., El Halawany, A.M., Ali, Z.Y., and El Bishbishy, M. (2016). Phenolic content and anti-hyperglycemic activity of pecan cultivars from Egypt. Pharm. Biol. 54(5): 788-198.

Herrera, E.A. (1995). Pecan Growing in the Western United States. HortTechnology 5(3): 3-4.

Hilbig, J., Policarpi, P.B., Grinevicius, V.M.A.S., Mota, N.S.R.S., Toaldo, I., Luiz, M.T.B., Pedrosa, R.C., and Block, J.M. (2018). Aqueous extract from pecan nut [Carya illinoinensis (Wangenh) C. Koch] shell show activity against breast cancer cell line MCF-7 and Ehrlich ascites tumor in Balb-C mice. J. Ethnopharmacol. 211: 256-266.

Hudthagosol, C., Haddad, E., McCafthy, K., Wang, P., and Oda, K. (2010). Pecans acutely increase plasma postprandial antioxidant capacity and catechins and decrease LDL oxidation in humans. J. Nut. 141: $56-62$.

Idowu, O.J., Sanogo, S., and Brewer, C.E. (2017). Short term impacts of pecan waste byproducts on soil quality in texturally different arid soils. Commun. Soil Sci. Plant Anal. 48(15): 1781-1791.

International Nut and Dried FruitCouncil. (2016). International Nutand Dried FruitCouncilNutsand Dried Fruits, Global Statistical Review2015/2016. 
http://www.nutfruit.org/files/tech/Global-Statistical-Review2015-2016.pdf. Accessed 29 Mar. 2018.

Juhaimi, F.A., Özcan, M.M., Uslu, N., and Doğu, S. (2017). Pecan walnut (Carya illinoinensis (Wangenh.) K. Koch) oil quality and phenolic compounds as affected by microwave and conventional roasting. J. Food Sci. Technol. 54(13): 4436-4441.

Kornsteiner, M., Wagner, K.-H., and Elmadfa, I. (2006). Tocopherols and total phenolics in 10 different nut types. Food Chem. 98: 381-387.

Kris-Etherton, P.M., Zhao, R.D.G., Binkoski, A.E., Coval, S.M., and Etherton, T.D. (2001). The Effects of Nuts on Coronary Heart Disease Risk. Nutr. Rev. 59(4): 103-111.

Lamuel-Raventos, R.M., and St. Onge, M.-P. (2017). Prebiotic nut compounds and human microbiota. Crit. Rev. Food Sci. Nutr. 57(14): 3154-3163.

Lerma-Herrera, M.A., Núñez-Gastelum, J.A., Ascacio-Valdés, J., Aguilar, C.N., Rodrigo-García, J., Díaz-Sánchez, A.G., Alvarez-Parrilla, E., and de la Rosa, L.A. (2017). Estimation of the mean degree of polymerization of condensed tannins from the kernel and shell of Carya illinoinensis by HPLC/MS and spectrophotometric methods. Food Anal. Methods. 10(9): 3023-3031.

Lillywhite, J.M., Simonsen, J.E., and Heerema, R.J. (2014). U.S. Consumer Purchases and Nutritional Knowledge of Pecans. HortTechnology. 24: 222-230.

Martinez-Gonzalez, A.I., Díaz-Sánchez, A.G., De la Rosa, L.A., Vargas-Requena, C.L., Bustos-Jaimes, I., and Alvarez-Parrilla, E. (2017). Polyphenolic compounds and digestive enzymes: In vitro non-covalent interactions. Molecules. 22(4): 669.

Mathur, P., Ding, Z., Saldeen, T., and Mehta, J.L. (2015). Tocopherols in the prevention and treatment of atherosclerosis and related cardiovascular disease. Clin. Cardiol. 38(9): 570-576.

Miller, A.A., Verghese, M., Boateng, J., Shackelford, L., and Walker, L.T. (2010). Feeding almonds and pecans reduced development oof azoxymethane induced precancerous lesions. Int. J. Cancer Res. 6(4): 234-242.

Miraliakbari, H., and Shahidi, F. (2008a). Antioxidant activity of minor components of tree nut oils. Food Chem. 111: 421-427.

Miraliakbari, H., and Shahidi, F. (2008b). Lipid class compositions, tocopherols and sterols of tree nut oils extracted with different solvents. J. Food Lipids. 15: 81-96.

Miraliakbari, H., and Shahidi, F. (2008c). Oxidative stability of tree nut oils. J. Agric. Food Chem. 56: 4751-4759.

Morgan, W.A., and Clayshulte, B.J. (2000). Pecan lower low-density lipoprotein cholesterol in people with normal lipid levels. J. Am. Diet. Assoc. 100(3): 312-318.

Mukuddem-Petersen, J., Oosthuizen, W., and Jerling, J.C. (2005). A systematic review of the effects of nuts on blood lipid profiles in humans. J. Nut. 135: 2082-2089.

Müller, L.G., Pase, C.S., Reckziegel, P., Barcelos, R.C.S., Boufleur, N., Prado, A.C.P., Fett, R., Block, J.M., Pavanato, M.A., Bauermann, L.F., da Rocha, J.B.T., and Burger, M.E. (2013). Hepatoprotective effects of pecan nut shells on ethanol-induced liver damage. Exp. Toxicol. Pathol. 65: 165-171.

Nackz, M., and Shahidi, F. (2004). Extraction and analysis of phenolics in food. J. Chromatogr. A 1054: 95-111.

Núñez, M.J.H., Valdez, G.B., Martínez, D.G., and Valenzuela, C.E. (2001). El nogal pecanero en Sonora, México. In SAGARPA, INIFAP. Folleto técnico No. 3. Instituto Nacional de Investigaciones Forestales, Agrícolas y Pecuaria.

Orona-Castillo, I., Espinoza-Arellano, J.J., González-Cervantes, G., MurilloAmador, B., García-Hernández, J.L., and Santamaría-César, J. (2006). Technical and socioeconomic aspects of pecan nut production (Carya illinoensis Koch.) in the Comarca Lagunera region, Mexico. Agric. Tec. Mex. 32(3): 295-301.

Osorio, E., Flores, M., Hernández, D., Ventura, J., Rodríguez, R., and Aguilar, C.N. (2010). Biological efficiency of polyphenolic extracts from pecan nuts shell (Carya Illinoensis), pomegranate husk (Punica granatum) and creosote bush leaves (Larrea tridentata Cov.) against plant pathogenic fungi. Ind. Crops Prod. 31: 153-157.

Pérez-Fernández, V., Spagnoli, M., Rocco, A., Aturkis, Z., Sciubba, F., De Salvador, F.R., Engel, P., Curini, R., and Gentili, A. (2017). Non-aqueous reversed-phase liquid-chromatography of tocopherols and tocotrien- ols and their mass spectrometric quantification in pecan nuts. J. Food Comp. Anal. 64: 171-180.

Porto, L.C.S., da Silva, J., Ferraz, A.B.F., Ethur, E.M., Porto, C.D.L., Marroni, N.P., and Picada, J.N. (2015a). The Antidiabetic and Antihypercholesterolemic Effects of an Aqueous Extract from Pecan Shells in Wistar Rats. Plant Foods for Hum. Nutr. 70: 414-419.

Porto, L.C.S., da Silva, J., Sousa, K., Ambrozio, M.L., de Almeida, A., dos Santos Alves, C.E., Dias, J.F., Allgayer, M.C., dos Santos, M.S., Pereira, P., Ferraz, A.B.F., and Picada, J.N. (2015b). Evaluation of Toxicological Effects of an Aqueous Extract of Shells from the Pecan Nut Carya itlinoinensis (Wangenh.) K. Koch and the Possible Association with Its Inorganic Constituents and Major Phenolic Compounds. Evid. Based Complement. Alternat. Med. 2016: 4647830.

Porto, L.C.S., de Silva, J., Ferraz, A.B.F., Correa, D.S., dos Santos, M.S., Porto, C.D.L., and Picada, J.N. (2013). Evaluation of acute and subacute toxicity and mutagenic activity of the aqueous extract of pecan shells [Carya illinoinensis (Wangenh.) K. Koch]. Food Chem. Toxicol. 59: 579-585.

Rajaram, S., Burke, K., Connell, B., Myint, T., and Sabaté, J. (2001). A Monounsaturated Fatty Acid-Rich Pecan-Enriched Diet Favorably Alters the Serum Lipid Profile of Healthy Men and Women. J. Nut. 131(9): 2275-2279.

Rajaram, S., and Sabaté, J. (2006). Nuts, body weight and insulin resistance. Br. J. Nutr. 96(Suppl 2): S79-S86.

Reckziegel, P., Boufleur, N., Barcelos, R.C.S., Benvegnú, D.M., Pase, C.S., Müller, L.G., Teixeira, A.M., Zanella, R., Prado, A.C.P., Block, J.M., and Burger, M.E. (2011). Oxidative stress and anxiety-like symptoms related to withdrawal of passive cigarette smoke in mice: Beneficial effects of pecan nut shells extract, a by-product of the nut industry. Ecotoxicol. Environ. Saf. 74: 1770-1778.

Robbins, K.S., Gong, Y., Wells, L.M., Greenspan, P., and Pegg, R.B. (2015). Investigation of the antioxidant capacity and phenolic constituents of U.S. pecans. J. Funct. Foods. 15: 11-22.

Robbins, K.S., Greenspan, P., and Pegg, R.B. (2016). Effect of pecan phenolics on the release of nitric oxide from murine RAW 264.7 macrophage cells. Food Chem. 212: 681-687.

Robbins, K.S., Ma, Y., Wells, L.M., Greenspan, P., and Pegg, R.B. (2014). Separation and characterization of phenolic compounds from U.S. pecans by Liquid Chromatography-Tandem Mass Spectrometry. J. Agric. Food Chem. 62: 4332-4341.

Ryan, E., Galvin, K., ÓConnor, T.P., Maguire, A.R., and ÓBrien, N.M. (2006). Fatty acid profile, tocopherol, squalene and phytosterol content of brazil, pecan, pine, pistachio and cashew nuts. Int. J. Food Sci. Nutr. 57(3/4): 219-228.

Salvador, A.A., Podestá, R., Block, J.M., and Ferreira, S.R.S. (2016). Increasing the value of pecan nut [Carya illinoinensis (Wangenh) C.Koch] cake by means of oil extraction and antioxidant activityevaluation. J. Supercrit. Fluids. 116: 215-222.

Sarkis, J.R., Correa, A.P., Michel, L., Brandelli, A., Tessaro, I.C., and Marczak, L.D.F. (2014). Evaluation of the Phenolic Content and Antioxidant Activity of Different Seed and Nut Cakes from the Edible Oil Industry. J. Am. Oil Chem. Soc. 91: 1773-1782.

Sauceda, A.E.Q., Sáyago-Ayerdi, S.G., Ayala-Zavala, J.F., Wall-Medrano, A., de la Rosa, L.A., González-Aguilar, G.A., and Alvarez-Parrilla, E. (2018). Biological Actions of Phenolic Compounds. In: Yahia, E.M. (Ed.) Fruit and Vegetable Phytochemicals. Chemistry and Human Health. John Wiley and Sons Ltd, Hoboken, NJ, pp. 286-307.

Scapinello, J., Magro, J.D., Block, J.M., Luccio, M.D., Tres, M.V., and Oliveira, J.V. (2017). Fatty acid profile of pecan nut oils obtained from pressurized n-butane and cold pressing compared with commercial oils. Journal of Food Sci. Technol. 54(10): 3366-3369.

Secretaría de Economía. (2015). Secretaría de EconomíaSIAVI, Sistema de Información Arancelaría Vía Internet. http://www.economia-snci. gob. mx/ Accessed 29 Mar. 2018.

Shahidi, F., and Ambigaipalan, P. (2015). Phenolics and polyphenolics in foods, beverages and spices: Antioxidant activity and health effects -A review. J. Funct. Foods 18: 820-897.

SIAP, Servicio de Informaci\&\#xf3;n Agroalimentaria y Pesquera. (2016). SIAP, Servicio de Información Agroalimentaria y PesqueraAnuario Estadístico de la Producción Agrícola. http://nube.siap.gob.mx/cierre agricola/ Accessed 29 Mar. 2018. 
Song, S., Cheong, L.-Z., Wang, H., Man, Q.-Q., Pang, S.-J., Li, Y.-Q., Ren, B., Wang, Z., and Zhang, J. (2018). Characterization of phospholipid profiles in six kinds of nut using HILIC-ESIIT-TOF-MS system. Food Chem. 240: 1171-1178.

Sparks, D. (2005). Adaptability of Pecan as a Species. Hortscience 40(5): 1175-1189.

Stone, D.E. (1997). Carya illinoinensis. In: Flora of North America Editorial Committee (Ed.) Flora of North America North of Mexico, Oxford University Press, Oxford, pp. 416-425.

Suchy, J., Lee, S., Ahmed, A., and Shea, T.B. (2010). Dietary supplementation with pecans delays motor neuron pathology in transgenic mice expressing G93A mutant human Superoxide Dismutase-1. Cur. Top. Nutr. Res. 8(1): 45-54.

Toro-Vazquez, J.F., Charó-Alonso, M.A., and Pérez-Briceno, F. (1999). Fatty acid composition and its relationship with physicochemical properties of pecan (Carya illinoensis) oil. J. Am. Oil Chem. Soc. 76(9): 957-965.

Trevisan, G., Rossato, M.F., Hoffmeister, C., Müller, L.G., Pase, C.S., Córdova, M.M., Rosa, F., Hausen, B.S., Boligon, A.A., Morescco, R.N., Athayde, M.L., Burguer, M.E., Santos, A.R., and Ferreira, J. (2014). Antinociceptive and antiedematogenic effect of pecan (Carya illinoensis) nut shell extract in mice: a possible beneficial use for a byproduct of the nut industry. J. Basic Clin. Physiol. Pharmacol. 25(4): 401-410.

Trevizol, F., Benvegnú, D.M., Barcelos, R.C.S., Pase, C.S., Segat, H.J., Dias, V.T., Dolci, G.S., Boufleur, N., Reckziegel, P., and Bürger, M.E. (2011). Comparative study between two animal models of extrapyramidal movement disorders: Prevention and reversion by pecan nut shell aqueous extract. Behav. Brain Res. 221: 13-18.

UPOV, Union for the Protection of New Varieties of Plants. (2017). UPOV, Union for the Protection of New Varieties of PlantsPLUTO: Plant Variety Database. http://www.upov.int/portal/index.html.en. Accessed 29 Mar. 2018.

USDA, Agricultural Research Service. (2017). USDA, Agricultural Research ServiceNational Collection of Genetic Resources for Pecans and Hickories. https://www.ars.usda.gov/plains-area/college-station-tx/ southern-plains-agricultural-research-center/crop-germplasm-research/docs/national-collection-of-genetic-resources-pecans-andhickories/. Accessed 29 Mar. 2018.

USDA, Agricultural Research Service, Nutrient Data Laboratory. (2016).
USDA, Agricultural Research Service, Nutrient Data LaboratoryUSDA National Nutrient Database for Standard Reference, Release 28. Version Current: September 2015, slightly revised May 2016. https:// ndb.nal.usda.gov/ndb/search/list. Accessed 29 Mar. 2018.

Van Loo, E.J., Babu, D., Crandall, P.G., and Ricke, S. (2012). Screening of commercial and Pecan Shell-Extracted Liquid Smoke agents as natural antimicrobials against foodborne pathogens. J. Food Prot. 75(6): 1148-1152.

Vázquez-Flores, A.A., Wong-Paz, J.E., Lerma-Herrera, M.A., MartinezGonzalez, A.I., Olivas-Aguirre, F.J., Aguilar, C.N., Wall-Medrano, A., González-Aguilar, G.A., Alvarez-Parrilla, E., and de la Rosa, L.A. (2017). Proanthocyanidins from the kernel and shell of pecan (Carya illinoinensis): Average degree of polymerization and effects on carbohydrate, lipid and peptide hydrolysis in a simulated human digestive system. J. Funct. Foods. 28: 227-234.

Vendrame, W. and Wetzstein, H. (2005). Carya illinoinensis Pecan. In: Litz, R.E. (Ed.) Biotechnology of fruit and nut crops. CABI Publishing, pp. 298-306.

Villarreal-Lozoya, J.E., Lombardini, L., and Cisneros-Zevallos, L. (2007). Phytochemical constituents and antioxidant capacity of different pecan [Carya illinoinensis (Wangenh.) K. Koch] cultivars. Food Chem. 102: 1241-1249.

Wells, L. (2014). Pecan Planting Trends in Georgia. HortTechnology 24(4): $475-479$.

Wells, L. (2017a). The Legacy of Antoine. In: U. o. A. Press (Ed.) Pecan: America's Native Nut Tree University of Alabama Press, Alabama, pp. 31-60.

Wells, L. (2017b). Origins of the Pecan. In: U. o. A. Press (Ed.) Pecan: America's Native Nut Tree University of Alabama Press, Alabama, pp. $1-31$.

Wood, B.W., Grauke, L.J., and Payne, J.A. (1998). Provenance Variation in Pecan. J. Am. Soc. Hort. Sci. 123(6): 1023-1028.

Wood, B.W., Payne, J.A., and Grauke, L.J. (1990). The rise of the U.S. pecan industry. Hortscience 25(6): 721-723.

Yang, J., Liu, R.H., and Halim, L. (2009). Antioxidant and antiproliferative activities of common edible nut seeds. LWT. Food Sci. Technol. 42 : $1-8$.

Zhao, X., Liu, A., Zhang, W., Lv, S., and Ren, K. (2011). The effect of pecan oil on hippocampal cells apoptosis of ovariectomized rats. Procedia Eng. 18: 375-380. 